\title{
Cell-specific gene expression in Anabaena variabilis grown phototrophically, mixotrophically, and heterotrophically
}

Jeong-Jin Park ${ }^{1,2,6}$, Sigal Lechno-Yossef ${ }^{1,3}$, Coleman Peter Wolk ${ }^{1,3,4}$ and Claire Vieille ${ }^{1,2,5^{*}}$

\begin{abstract}
Background: When the filamentous cyanobacterium Anabaena variabilis grows aerobically without combined nitrogen, some vegetative cells differentiate into $\mathrm{N}_{2}$-fixing heterocysts, while the other vegetative cells perform photosynthesis. Microarrays of sequences within protein-encoding genes were probed with RNA purified from extracts of vegetative cells, from isolated heterocysts, and from whole filaments to investigate transcript levels, and carbon and energy metabolism, in vegetative cells and heterocysts in phototrophic, mixotrophic, and heterotrophic cultures.

Results: Heterocysts represent only $5 \%$ to $10 \%$ of cells in the filaments. Accordingly, levels of specific transcripts in vegetative cells were with few exceptions very close to those in whole filaments and, also with few exceptions (e.g., nif1 transcripts), levels of specific transcripts in heterocysts had little effect on the overall level of those transcripts in filaments. In phototrophic, mixotrophic, and heterotrophic growth conditions, respectively, 845, 649, and 846 genes showed more than 2 -fold difference $(p<0.01)$ in transcript levels between vegetative cells and heterocysts. Principal component analysis showed that the culture conditions tested affected transcript patterns strongly in vegetative cells but much less in heterocysts. Transcript levels of the genes involved in phycobilisome assembly, photosynthesis, and $\mathrm{CO}_{2}$ assimilation were high in vegetative cells in phototrophic conditions, and decreased when fructose was provided. Our results suggest that Gln, Glu, Ser, Gly, Cys, Thr, and Pro can be actively produced in heterocysts. Whether other protein amino acids are synthesized in heterocysts is unclear. Two possible components of a sucrose transporter were identified that were upregulated in heterocysts in two growth conditions. We consider it likely that genes with unknown function represent a larger fraction of total transcripts in heterocysts than in vegetative cells across growth conditions.

Conclusions: This study provides the first comparison of transcript levels in heterocysts and vegetative cells from heterocyst-bearing filaments of Anabaena. Although the data presented do not give a complete picture of metabolism in either type of cell, they provide a metabolic scaffold on which to build future analyses of cell-specific processes and of the interactions of the two types of cells.
\end{abstract}

Keywords: Anabaena variabilis, Amino acid biosynthesis, Vegetative cell, Heterocyst, Transcript levels, Microarray

\footnotetext{
* Correspondence: vieille@msu.edu

${ }^{1}$ Great Lakes Bioenergy Research Center, Michigan State University, East

Lansing, MI 48824, USA

${ }^{2}$ Department of Microbiology \& Molecular Genetics, Michigan State

University, East Lansing, MI 48824, USA

Full list of author information is available at the end of the article
} 


\section{Background}

Anabaena variabilis ATCC 29413 is a well-studied, genetically tractable [1], filamentous cyanobacterium. Its vegetative cells photosynthesize and fix $\mathrm{CO}_{2}$. In the presence of oxygen $\left(\mathrm{O}_{2}\right)$ and absence of a source of combined nitrogen, $A$. variabilis fixes atmospheric nitrogen $\left(\mathrm{N}_{2}\right)$ in specialized cells called heterocysts that differentiate from vegetative cells. The semi-regularly spaced heterocysts comprise about $5 \%-10 \%$ of all cells in the filament $[2,3]$. Heterocysts are thought to maintain a microoxic interior by three mechanisms: they (i) form a thick envelope of glycolipid and polysaccharide that reduces the rate of entry of $\mathrm{O}_{2}$, (ii) respire actively, and (iii) stop producing $\mathrm{O}_{2}$ [4,5]. Their microoxic interior permits $\mathrm{N}_{2}$ fixation by nitrogenase, a highly $\mathrm{O}_{2}$-sensitive enzyme. Hydrogen $\left(\mathrm{H}_{2}\right)$ produced by nitrogenase is largely reassimilated by an uptake hydrogenase, Hup. $\mathrm{N}_{2}$ fixed in heterocysts is assimilated through the glutamine synthetase-glutamate synthase (GS-GOGAT) pathway, and glutamine is considered a main nitrogenous product transported to vegetative cells. In exchange, vegetative cells have been thought to transfer sucrose and glutamate to the heterocysts [6-9]. In the light, ferredoxin reduced by photosystem I (PS I) is the likely source of electrons for $\mathrm{N}_{2}$ fixation [10], but the metabolic pathway or pathways that transfer electrons to PS I in heterocysts are not known.

Knowledge of cell-specific metabolism in A. variabilis and its relatives has been obtained in large part from studies of enzyme assays, the expression of individual genes, and other genetic approaches [4,11-15]. Numerous studies have focused on regulatory mechanisms governing heterocyst development [14-19] rather than on the metabolism of mature heterocysts. Recent studies have sought a genome-wide understanding of cell-specific metabolism in these cyanobacteria. The first such effort, performed with $A$. variabilis's close relative, Anabaenal Nostoc sp. strain PCC 7120 [20] (hereafter called PCC 7120), used microarrays comprising 3-kb DNA fragments covering approximately $90 \%$ of the chromosome. The authors compared transcript levels in filaments and in a heterocyst-enriched fraction; the multi-gene features used on the microarrays limited the interpretation of the results. Microarray studies of PCC 7120 [21] and Nostoc punctiforme [22] used gene-specific probes and compared gene transcript levels in different growth conditions, but did not attempt to characterize transcript levels in different types of cells. A recent microarray study of PCC 7120 that emphasized growth conditions favoring circadian gene expression [23] characterized transcript levels of several genes in a heterocyst-enhanced fraction $(80 \%$ heterocysts) versus filaments. RNA-sequencing methods were used to study transcript levels between 0 and $21 \mathrm{~h}$ [24] or 0 and $8 \mathrm{~h} \mathrm{[25]} \mathrm{of} \mathrm{nitrogen} \mathrm{stepdown} \mathrm{at} \mathrm{the} \mathrm{fila-}$ ment level but not in different types of cells. Proteomic analyses of related cyanobacteria [26-28] have unambiguously identified too few proteins (e.g., 377 proteins in [27]) to validate the presence of entire pathways.

${ }^{13} \mathrm{C}$-based metabolic flux analysis, an excellent method for quantifying fluxes in central metabolic pathways $[29,30]$, has been applied to unicellular cyanobacteria using ${ }^{13} \mathrm{C}$-labeled $\mathrm{CO}_{2}$ [31]. Provided that one has sufficient knowledge of the amino acid biosynthetic pathways, and other principal pathways, that are active in heterocysts, the metabolism of heterocyst-containing filamentous cyanobacteria can also potentially be studied by metabolic flux analysis by using the ability of $A$. variabilis to assimilate fructose [32,33]. Very recently, PCC 7120 was shown to grow, albeit exceedingly slowly, when provided with 0.1 or $0.2 \mathrm{M}$ fructose in the dark [34]. It can grow heterotrophically more rapidly when supplemented with fructose transport genes from $A$. variabilis, but still much more slowly than does A. variabilis [35]. A. variabilis was, therefore, used in our work. As an initial step, we investigated $A$. variabilis cultures grown phototrophically (in the light), mixotrophically (in the light with fructose), and heterotrophically (in the dark with fructose) in the absence of combined nitrogen. These conditions separate the effects of carbon source $\left(\mathrm{CO}_{2}\right.$ vs. fructose) from those of sources of energy and reductant (light vs. fructose) on transcript levels. Our intent is to use gene transcript patterns (i.e., variations of a gene's transcript levels in different cell types and conditions) identified in this study to model possible metabolic pathways of vegetative cells and mature heterocysts as well as intercellular metabolic networks. Transcript levels were compared in isolated heterocysts, in vegetative cells from heterocystbearing filaments (for which there was no precedent), and in whole heterocyst-bearing filaments (to test whether those measurements were consistent). Cell-specific gene transcript levels were analyzed with steady-state cultures, because steady-state cultures would be needed for metabolic flux analysis of $\mathrm{N}_{2}$-fixing $A$. variabilis filaments.

\section{Methods}

\section{Bacterial strain and growth conditions}

A. variabilis ATCC 29413 was grown in an eightfold dilution of the medium of Allen and Arnon [36,37] (AA/8). Phototrophic and mixotrophic cultures were grown under continuous illumination by Philips cool white fluorescent lamps, $60-70 \mu \mathrm{mol}$ photons $\mathrm{m}^{-2} \mathrm{~s}^{-1}$. Mixotrophic cultures were supplemented with $5 \mathrm{mM}$ fructose. Heterotrophic cultures were grown in the dark in the presence of $5 \mathrm{mM}$ fructose. Four hundred-ml phototrophic, mixotrophic, and heterotrophic cultures in 2.8-1 Fernbach flasks were inoculated from $50-\mathrm{ml}$ precultures grown in the same conditions. Cultures were inoculated at a concentration of $0.05 \mu \mathrm{g}$ chlorophyll $a \mathrm{ml}^{-1}$, and grown on a shaker at $30^{\circ} \mathrm{C}$ and $140 \mathrm{rpm}$. Actively growing filaments were harvested 
after seven days for phototrophic and heterotrophic cultures, and after four days for mixotrophic cultures. Dissolved oxygen was monitored in representative 400-ml cultures using an optical sensor system (Fluorometrix, Stow, MA) with a paper-thin, autoclavable luminescent oxygen sensor taped on the interior bottom surface of the flask, as described in the manufacturer's instructions.

\section{Separation of cell type-specific contents for RNA extraction}

Cultures $(400 \mathrm{ml})$ were sedimented at $500 \times g$ for $5 \mathrm{~min}$ at $4^{\circ} \mathrm{C}$, resuspended in $\sim 15 \mathrm{ml}$ RNAlater solution (Ambion, Austin, TX), and stored at $-80^{\circ} \mathrm{C}$. Once thawed, suspended filaments were sedimented $\left(500 \times g, 5 \mathrm{~min}, 4^{\circ} \mathrm{C}\right)$, resuspended in $50 \mathrm{ml}$ of $\mathrm{N}_{2}$-sparged $\mathrm{HP}$ buffer $(30 \mathrm{mM}$ Hepes/30 mM Pipes/1.0 mM MgCl $2, \mathrm{pH} 7.2$ ), and washed three times with $\mathrm{N}_{2}$-sparged $\mathrm{HP}$ buffer containing $10 \mathrm{mM}$ disodium ethylenediaminetetraacetic acid (HP/EDTA). Twenty percent of the suspension was used to extract RNA from whole filaments. The rest was used to isolate and extract heterocysts, by a modification of a published method [2], and to prepare vegetative cell-specific extracts. That method reported a final ratio of ca. 0.01 vegetative cells per heterocyst. The washed filaments were resuspended in $40 \mathrm{ml}$ of $\mathrm{HP} /$ EDTA containing $1 \mathrm{mg} \mathrm{ml}^{-1}$ lysozyme and were shaken at $30^{\circ} \mathrm{C}$ for $5 \mathrm{~min}$. The lysozyme-treated suspension was sedimented $(500 \times g$, $5 \mathrm{~min}, 4^{\circ} \mathrm{C}$ ), and the resulting pellet was resuspended in $10 \mathrm{ml}$ of HP buffer in a test tube. The tube was immersed in an ultrasonic cleaning bath (Model 8845-4, Cole-Palmer, Chicago, IL) and was subjected to cavitation for $3 \mathrm{~min}$ to destroy a fraction of the vegetative cells. Heterocysts and remaining vegetative cells were sedimented $\left(500 \times g, 5 \mathrm{~min}, 4^{\circ} \mathrm{C}\right)$, and the clear supernatant fluid (vegetative cell lysate) was saved on ice for extraction of vegetative cell-specific RNA. The sedimented cells were washed twice with HP/EDTA buffer. The washed cells were resuspended in $1 \mathrm{ml}$ of HP/EDTA containing $0.2 \mathrm{mg} \mathrm{ml}^{-1}$ lysozyme, shaken at $30^{\circ} \mathrm{C}$ for $25 \mathrm{~min}$, sedimented $\left(1,000 \times \mathrm{g}, 5 \mathrm{~min}, 4^{\circ} \mathrm{C}\right)$, and the pellet was resuspended in $1 \mathrm{ml}$ of HP buffer. This suspension was immersed in a $12^{\circ} \mathrm{C}$ sonic bath for $15 \mathrm{~min}$ to destroy remaining vegetative cells, and again sedimented $(1,000 \times g$, $5 \mathrm{~min}, 4^{\circ} \mathrm{C}$ ). The supernatant solution was discarded, and the heterocyst-containing pellet was washed three times with HP buffer. Images of the resuspended pellets confirmed a high ratio of heterocysts to fragments of heterocyst envelopes and what may be ruptured remains of vegetative cell or heterocyst protoplasts (not shown).

\section{RNA extraction}

RNA was extracted from whole filaments, isolated heterocysts, and vegetative cell extracts with the RiboPureBacteria kit (Ambion) as described [38]. Extracted RNA was purified with an RNeasy Mini kit (Qiagen, Valencia, $\mathrm{CA}$ ) and eluted in $30 \mu \mathrm{l}$ of water. RNA preparations were stored at $-80^{\circ} \mathrm{C}$ until use. All RNA extractions were performed on three biological replicates. RNA samples were quantified using a NanoDrop ND-1000 spectrophotometer (NanoDrop Technologies, Wilmington, DE).

\section{RNA quality and cell-specificity controls}

The separate purifications of total RNAs from vegetative cells and from heterocysts from the same culture took close to $5 \mathrm{~h}$. Because of this unavoidable time constraint, our experiments may provide reliable information only for RNAs that are stabilized by Ambion RNAlater and, perhaps, abundant. The quality of the extracted RNA was tested on an RNA 6000 Nano LabChip (Agilent Technologies, Santa Clara, CA) using a 2100 Bioanalyzer (Agilent Technologies). Reverse transcription followed by quantitative real time-PCR (RT-qPCR) was used to test the cell specificity of RNA extractions. The $r b c L$ gene (Ava_3907) was used as a vegetative cell-specific gene and nifK (Ava_3930) was used as a heterocyst-specific gene $[2,39]$. The RNAse P RNA gene $(r n p B)$, constitutively expressed in $A$. variabilis, was used as an internal control for data normalization [40]. In addition, PCR reactions were performed using RNA and cDNA as templates and $r n p B \_F$ and $r n p B \_\mathrm{R}$ as primers to control for possible contamination of our purified RNA samples with genomic DNA. The gene-specific primers (Additional file 1) were designed using Primer Express 3.0. First-strand cDNA was prepared by reverse transcription using Superscript II reverse transcriptase (Invitrogen, Carlsbad, CA) and a combination of random primers (Invitrogen). $1.5 \mu \mathrm{l}$ of reverse transcription reaction mixture was used for each RT-qPCR reaction. Each reaction mixture contained $2 \mu \mathrm{M}$ of each gene-specific primer and $7.5 \mu \mathrm{l}$ of Power SYBR green PCR master mix (Applied Biosystems, Foster City, CA). RT-qPCR was performed with the three biological replicates on an ABI 7900HT Fast Real-Time PCR System (Applied Biosystems). Relative fold changes in transcript levels were calculated using a standard curve for relative quantification (pools of 1 pg to $250 \mathrm{pg}$ of cDNA were used).

\section{Microarray experiments}

cDNA was synthesized from the twenty-seven RNA samples (three culture conditions, and triplicate RNA extractions from each of whole filaments, vegetative cells, and heterocysts) by the University of Wisconsin-Madison Gene Expression Center. DNA end-labeling, hybridization, scanning, and data normalization were performed by NimbleGen (Reykjavík, Iceland), which provided the final data file. Cy3-labeled cDNAs were hybridized to NimbleGen expression array chips (Product no. A438500-01) that represent 5,657 ORFs in the A. variabilis 
genome (GenBank accession no. CP000117) excluding a 49-ORF incision element (GenBank accession no. NC_014000). Each ORF was represented by seventeen 60-mer oligonucleotides. Each oligonucleotide was present four times on the array. The twenty-seven microarray data files were normalized against each other using quantile normalization [41]. Expression array data were analyzed using ArrayStar 3.0 (DNASTAR, Madison, WI). Microarray data have been deposited in the National Center for Biotechnology Information Gene Expression Omnibus database (http://www.ncbi.nlm.nih.gov/geo/, accession number GSE46076).

In this paper, upregulation of a gene in a given cell type means upregulation in comparison to the other cell type in the same condition(s). A gene will be said to be transcribed at background, just above background, very low, low, moderate, high, and very high levels in a particular condition when its normalized transcript level is in the range of $\leq 150,151-200,201-600,601-2,000$, $2,001-6,000,6,001-20,000$, or 20,001-60,000 signal intensity units (SIU after normalization) in that condition, respectively. A distinction between "background" and "just above background" is somewhat arbitrary: some genes in one of these categories may belong in the other.

\section{Statistical data analyses}

Principal component analysis (PCA) was performed in Statistica (version 7.0, StatSoft, Tulsa, OK). Cell types and culture conditions were set as categorical variables and transcript levels were set as continuous variables. Linear modeling of the transcript data in each growth condition was performed in $\mathrm{R}$ [42] using the function $F_{i}=a V_{i}+b H t_{i}-1$, where $F_{i}, V_{i}$, and $H_{t}$ represent the means of gene i transcript levels in filaments, vegetative cells, and heterocysts, respectively; $\mathrm{a}$ and $\mathrm{b}$ are constants that reflect the relative abundance of vegetative cells and heterocysts in the filaments; and -1 is a term that forces the intercept to 0. Calculations of Spearman's rank correlation coefficients [43], grid searching, and bootstrapping were performed in $\mathrm{R}$. Weighted residuals were calculated using Equation 1, where $R_{i}$ is the weighted residual of gene $\mathrm{i}, \mathrm{F}_{\mathrm{i}, \text { calc }}=\mathrm{aV}_{\mathrm{i}}+\mathrm{bHt}_{\mathrm{i}}$, and $\sqrt{V_{t}^{2}+H t_{t}^{2}+F_{t}^{2}}$ is the length of the $\left(\mathrm{V}_{\mathrm{i}}, \mathrm{Ht}_{\mathrm{i}}, \mathrm{F}_{\mathrm{i}}\right)$ vector in three-dimensional space.

$$
\mathrm{R}_{\mathrm{i}}=\frac{F_{i}-F_{i, \text { calc }}}{\sqrt{V_{t}^{2}+H t_{t}^{2}+F_{t}^{2}}}
$$

\section{Cell extracts and enzyme assays}

For enzyme assays of $A$. variabilis grown in phototrophic conditions, cultures were harvested by centrifugation when chlorophyll concentration reached $8 \mu \mathrm{g} / \mathrm{ml}$, and stored at $-80^{\circ} \mathrm{C}$. To prepare crude extracts from whole filaments, cells from 200-ml cultures were resuspended in $10 \mathrm{ml}$ lysis buffer $(50 \mathrm{mM}$ Tris- $\mathrm{HCl}, \mathrm{pH} 8.4$, containing $1 \mathrm{mM}$ phenylmethylsulfonyl fluoride and one protease inhibitor cocktail tablet [complete mini, EDTA-free, Roche Diagnostics, Indianapolis, IN]). Cells were lysed by two passages through a French press maintained at $4{ }^{\circ} \mathrm{C}(4,000$ to $5,000 \mathrm{psi})$. After centrifugation of the whole filament lysate $\left(2,000 \times g, 15 \mathrm{~min}, 4^{\circ} \mathrm{C}\right)$, the supernatant solution was dialyzed twice against $20 \mathrm{mM}$ Tris- $\mathrm{HCl}(\mathrm{pH} 7.2)$, with a total dialysis time of $24 \mathrm{~h}$ (SpectraPor dialysis tubing, 12,000-14,000 Da cut-off, Spectrum Laboratories, Rancho Dominguez, CA). Dialysis was required to remove phosphates from the lysate. The dialyzed filament lysate was used in enzyme assays. To prepare crude extracts of enriched heterocyst fractions, heterocysts were purified as described for RNA purification. Purified heterocysts were resuspended in $1.5 \mathrm{ml}$ lysis buffer and lysed using zirconia beads in a Mini-BeadBeater (Biospec Products, Bartlesville, $\mathrm{OK}$ ) on high speed setting (1 min, $4^{\circ} \mathrm{C}$ ). After centrifugation $\left(1,600 \times g, 10 \mathrm{~min}, 4^{\circ} \mathrm{C}\right)$, the supernatant solution-representing the soluble extract-was concentrated by ultrafiltration, and used for protein and enzyme activity assays. Protein concentrations were determined using the Bio-Rad protein assay kit (Bio-Rad, Richmond, CA), with bovine serum albumin as the standard.

Phosphoserine phosphatase activity was measured at $30^{\circ} \mathrm{C}$ as described [44], using 13-270 $\mu \mathrm{g}$ protein in each assay. The phosphate released was quantified using the malachite green method [45] on a DU-650 spectrophotometer (Beckman, Fullerton, CA).

\section{Results}

\section{Concentration of dissolved oxygen in cultures}

To avoid potential contaminations, particularly in cultures grown with fructose, cultures were shaken under ambient air, but not bubbled. Dissolved $\mathrm{O}_{2}$ was monitored during growth to confirm that cultures were fully aerobic (data not shown). Between inoculation and harvest, the dissolved $\mathrm{O}_{2}$ in phototrophic and mixotrophic cultures increased from $6.1 \mathrm{mg} \mathrm{l}^{-1}$ just after inoculation to $7.5 \mathrm{mg} \mathrm{l}^{-1} \mathrm{O}_{2}$ at harvest time $\left(7.5 \mathrm{mg} \mathrm{l}^{-1}\right.$ is the $\mathrm{O}_{2}$ saturation value at $30^{\circ} \mathrm{C}$ ). The dissolved $\mathrm{O}_{2}$ in heterotrophic cultures varied between $6.1 \mathrm{mg} \mathrm{l}^{-1}$ and $6.3 \mathrm{mg} \mathrm{l}^{-1}$ during the entire growth period.

\section{Quality and cell-specificity of RNA extractions}

Only heterocyst RNAs from phototrophic cultures showed evidence of degradation, with most of the degraded RNA species over $200 \mathrm{nt}$ long (Additional file 2: Figure S1). Because reverse transcription of bacterial RNA used random primers, and because each gene on the microarray was represented by seventeen probes, microarray experiments were nonetheless likely to capture most of the abundant 
RNAs. RNA extractions from heterocysts of phototrophic cultures, repeated for nine biological replicates, yielded similar degradation results. The samples that looked the least degraded were used for microarray experiments. Heterocyst RNAs from phototrophic cultures show, otherwise, trends in transcript levels very similar to those observed with heterocyst RNAs from mixotrophic and heterotrophic cultures (see Overall microarray assessment section), suggesting that RNA degradation in extracts from phototrophic cultures is not a major limitation in our experiments. PCR reactions using RNA samples as templates never showed a PCR band and always showed a PCR band with CDNA controls (data not shown), indicating that our RNA preparations were devoid of contamination by genomic DNA.

The cell specificity of our RNA preparations was tested by RT-qPCR. We chose nifK and $r b c L$ as cell specificity marker genes because it is well established that under oxic conditions nifK is expressed only in heterocysts and $r b c L$ is expressed mostly, perhaps only, in vegetative cells $[4,14]$. Ct (threshold cycle) values for $r n p B$ did not vary by more than $5 \%$ between heterocysts and vegetative cells in all three growth conditions (not shown), validating our choice of $r n p B$ as a constitutively expressed gene that can be used to normalize the transcript levels of other genes across experiments. The relative $r b c L$ signals obtained from heterocyst RNA were only $7.6 \%$ and $6.9 \%$ of those obtained from vegetative cell RNA in phototrophic and mixotrophic cultures, respectively (Figure 1). In contrast, the relative nifK signals obtained from vegetative cell RNA were only $11.8 \%$ and $10.1 \%$ of those obtained from heterocyst RNA in phototrophic and mixotrophic cultures, respectively. A conservative interpretation of these results is that heterocyst RNA preparations were over 9\% and over 93\% cell-specific for phototrophic and mixotrophic conditions, respectively. Vegetative cell RNA preparations were over $88 \%$ and $89 \%$ cell-specific for phototrophic and mixotrophic conditions, respectively. With heterotrophic cultures, the cell specificity of heterocyst RNA and vegetative cell RNA preparations never appeared to be above $83 \%$, even though RNA extractions were repeated eight times, each time making the first lysis step gentler and the last lysis step harsher to better separate RNA from the two cell types.

If a transcript is more abundant in filaments than in vegetative cells, and yet this transcript is only modestly more abundant-or even less abundant-in heterocysts than in filaments, the heterocyst level of that transcript is likely under-represented in our experiments (examples, including nitrogenase [nif1] transcripts, are presented below). When transcript levels in whole filaments are consistent with transcript levels in vegetative cells and heterocysts, and in particular when specific genes are transcribed at high levels

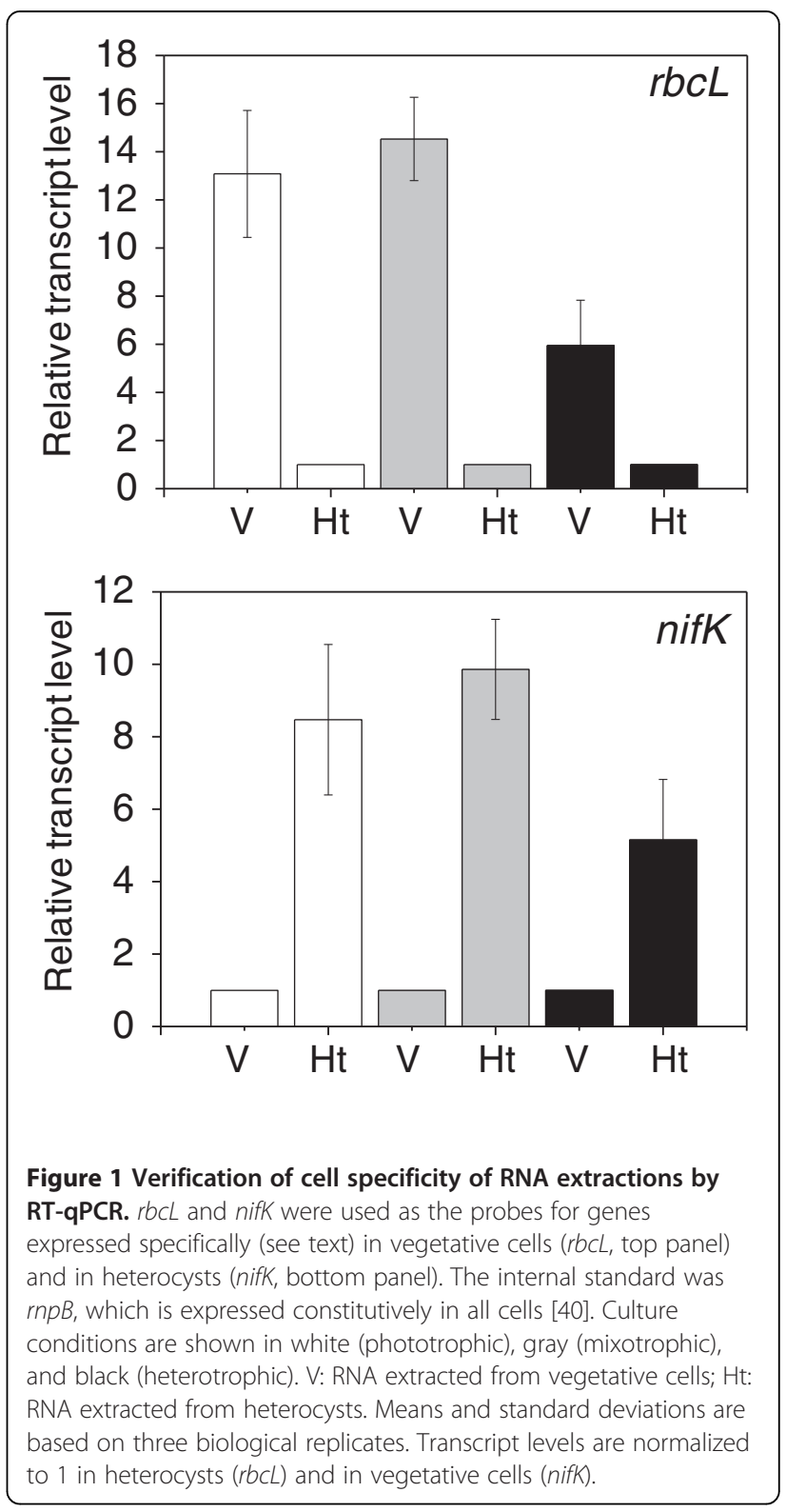

across cell types and growth conditions, and in the absence of contradictory information, we consider those genes-or whole pathways-active in heterocysts. On the other hand, transcript levels only slightly above background level in heterocysts will not be considered as evidence that genes or intact pathways are active in heterocysts, even though they may be. We are trying to be conservative in our interpretations in this first effort to use microarray data to identify active pathways in vegetative cells and heterocysts of $\mathrm{N}_{2}$-fixing filaments, especially because the importance of major enzymatic pathways (including nitrogen fixation, the processing of sucrose by invertase, the oxidative pentose phosphate cycle, and cytochrome oxidase activity) might otherwise be misinterpreted. 


\section{Overall microarray assessment}

The experimental metrics report provided by NimbleGen (not shown) gives summary statistics that can be used to help identify potential problems during hybridization. All metrics for the twenty seven microarray experiments were within the manufacturer's suggested ranges.

The normalized microarray data are shown in Additional file 3 . The coefficients of determination ( $\mathrm{R}^{2}$ values) between the twenty seven experiments were calculated to quantify experimental variability between biological replicates (Additional file 4). Reproducibility was high for biological replicates of the same experiment, as indicated by $R^{2}$ values ranging between 0.857 and 0.998 . The $R^{2}$ values between microarrays using heterocyst RNAs isolated from different culture conditions were also high, between 0.827 and 0.976 . These results also include the experiments with the partially degraded heterocyst RNAs extracted from phototrophic cultures, suggesting that partial degradation of the RNA has only a minor effect on overall hybridization results. The $\mathrm{R}^{2}$ values between microarrays using vegetative cell RNAs and whole filament RNAs isolated from the same culture types also were high, between 0.876 and 0.994 , reflecting the fact that filaments comprise mostly vegetative cells. In contrast, microarray results varied more when comparing vegetative cell RNAs extracted from different types of cultures $\left(R^{2}\right.$ values between 0.542 and 0.817 ) or when comparing heterocyst and vegetative cell RNAs from the same cultures $\left(R^{2}\right.$ values between 0.400 and 0.871 ). These results make sense based on the respective metabolic functions of vegetative cells and heterocysts (see explanation below).

In all growth conditions and for each cell type, signal intensities were not normally distributed (Figure 2, left panels). A high number of genes with low intensity signals ( $\log _{2}$ [intensity] below 7.0) is found across all experiments, independent of cell type and culture condition, and may correspond to genes whose RNA is disproportionately labile. The proportion of genes with low signal intensity in the heterocysts of phototrophic cultures is not higher than it is in vegetative cells or whole filaments in the same culture conditions (Figure 2, top left panel). This observation suggests that the poorer quality of the RNA extracted from the heterocysts of phototrophic cultures did not substantially bias the results.

Microarray experiments with RNA from whole filaments were used to validate the results of the experiments performed with cell-specific RNA. In $\mathrm{N}_{2}$-fixing A. variabilis filaments, transcript levels of any gene, i, should be consistent with the equation, $F_{i}=a V_{i}+b H t_{i}$. Assuming that heterocysts and vegetative cells contain similar amounts of RNA and assuming that RNA is extracted with the same yield from whole filaments, vegetative cells, and heterocysts, $a+b$ should equal 1 , with the a-value ranging between 0.9 and 1 and the b-value ranging between 0 and 0.1 . Linear modeling was applied to reduced data sets (Additional file 5), where genes that showed average transcript levels below 128 across experiments and genes with high variability between biological replicates were removed (see Additional file 6 for details). The values of $\mathrm{a}$ and $\mathrm{b}$ were determined for the three growth conditions (Additional file 6). With the exceptions that the a-value was above 1 in phototrophic and heterotrophic conditions and the b-value was below 0 in heterotrophic conditions, the calculated values for a and $b$ were generally in the ranges expected from the frequency of heterocysts in filaments (i.e., $\mathrm{a} \sim 0.92$ and $\mathrm{b} \sim 0.08)$. Although we do not know whether heterocysts and vegetative cells have the same amounts of mRNA, equal amounts of cDNA were used in all hybridization experiments, possibly biasing the values of $a$ and $b$ during linear modeling. Our results remain consistent with the idea that for most genes the transcript level of a gene in heterocysts contributes little to the transcript level of this gene in whole filaments. Thus for most genes, transcript levels in whole filaments closely approximate transcript levels in vegetative cells.

In phototrophic and mixotrophic conditions, few genes in the reduced data set behaved as outliers, with transcript level data that did not closely conform to the equation $F_{i}=\mathrm{aV}_{\mathrm{i}}+\mathrm{bHt}_{\mathrm{i}}$. (Outliers are not discussed for heterotrophic conditions because the value of $b$ was not reliable: see Additional file 6). Deviation from the linear equation suggests that RNA is degraded in one type of cell or the other. The most conspicuous outliers (i.e., the points farthest from the plane defined by $\mathrm{F}=\mathrm{aV}+\mathrm{bH}_{\mathrm{t}}$ ) were identified in each growth condition by calculating weighted residuals as a proportion of each gene's transcript level using equation 1 (Additional file 6). Two sets of outlier genes in phototrophic conditions warrant mention. The nif1 genes, nifB, $S, U, H, D, K, E, N, X$, and $W$ (Ava_3912, Ava_3914-3917, Ava_3930, Ava_3932-3934, and Ava_3937, respectively) were the $3^{\text {rd }}$ to $12^{\text {th }}$ outliers for which $F_{i}>>a V_{i}+b H t_{i}$. The transcript levels of nif1 genes and of related maturation genes should be strongly upregulated in heterocysts compared to vegetative cells $[2,39,46]$, and the signal intensities for these genes should be ca. 10-fold lower in whole filaments than in heterocysts. Instead-especially in phototrophic conditions-signal intensities for nif1 genes were nearly always higher in whole filaments than in heterocysts, implying that the signal intensities in heterocysts were at least 10-fold lower than expected. This observation suggests that the nif1 transcripts are specifically targeted for rapid degradation in heterocysts upon separation of the heterocysts from vegetative cells under aerobic conditions. Transcripts of nif1 genes may represent a large fraction of the degraded transcripts seen in heterocysts of phototrophic cultures (Additional file 2: Figure S1). These results might be related to the degradation of nifHDK 

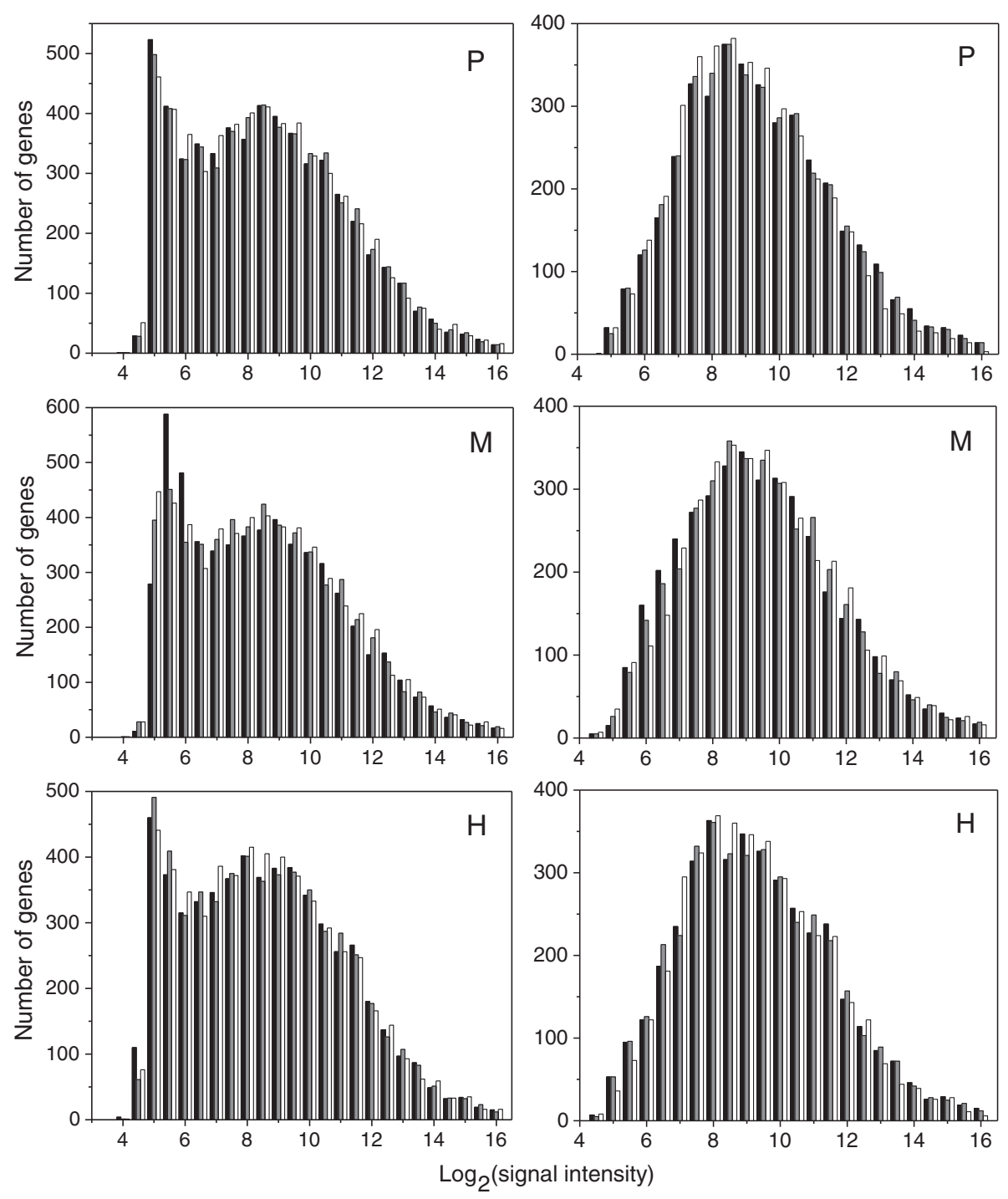

Figure 2 Histograms of the $\log _{2}$ values of the normalized average signal intensities for all microarray experiments. (P): Phototrophic cultures; (M): mixotrophic cultures; and (H): heterotrophic cultures. Black: signal distribution in whole filaments; gray: signal distribution in vegetative cells; and white: signal distribution in heterocysts. Left panels: all genes; right panels: reduced sets of genes (see Additional files 5 and 6; P: 3,949 genes; M: 3,885 genes, and H: 3,933 genes).

transcripts observed in PCC 7120 [47]. Because certain nif1 transcripts accumulated to up to $44 \%$ of the most abundant transcript in heterocysts in these conditions (consistent with the very large amount of protein attributable to Nif in non-denaturing gels of $A$. variabilis heterocysts [2]), the seemingly artificially low transcript levels for nif1 genes likely caused a factitious increase of transcript levels for all other genes in the heterocysts of phototrophic cultures. Therefore, moderate upregulation (below 5-fold) of genes other than nif1 in the heterocysts of phototrophic cultures may not be meaningful. Second, five PS II genes (Ava_4121, Ava_0593, Ava_1597, Ava_3553, and Ava_2460, four of them $p s b A$ genes) are the top two and the top $13^{\text {th }}$ to $15^{\text {th }}$ outliers. These genes have signal intensities in filaments that are 1.6- to 38 -fold lower than in vegetative cells. This trend in transcript levels of $p s b A$ genes is reminiscent of what happens in cyanobacteria subjected to oxidative damage (see Targeted analysis-Photosystems).

\section{General analysis of microarray results}

The only other use made of the reduced data sets (Additional files 5 and 6) was to highlight the differences in transcript levels between vegetative cells and heterocysts in the different growth conditions using volcano 
plots (Additional file 2: Figure S2). P values for those plots were calculated using two-tailed t-tests with unequal variances. Two hundred eighty, 144, and 545 genes were significantly upregulated (over 2-fold difference with $\mathrm{p}<0.01$ ) in vegetative cells in phototrophic, mixotrophic, and heterotrophic cultures, respectively. Of these genes, $22.5 \%$ to $24.3 \%$ had unknown products. Five hundred sixty five, 505, and 301 genes were significantly upregulated (over 2 -fold difference with $\mathrm{p}<0.01$ ) in heterocysts in phototrophic, mixotrophic, and heterotrophic cultures, respectively. Of these, 36.8\% (in phototrophic conditions) to $46.2 \%$ (in heterotrophic conditions) were genes with unknown products. Of the genes with unknown products that were upregulated in one type of cell versus the other, $77 \%, 86 \%$, and $51 \%$ were upregulated in the heterocysts in phototrophic, mixotrophic, and heterotrophic conditions, respectively. In summary, although transcript levels in vegetative cells and heterocysts are highly correlated (Additional file 6), many genes were significantly upregulated in one cell type versus the other in each growth condition.

PCA was used to determine how gene transcript patterns relate to cell type and culture conditions. In the three culture conditions, principal components for the whole filament were close to those for vegetative cells, but not to those for heterocysts (Figure 3), agreeing with the fact that vegetative cells typically represent $90 \%$ to $95 \%$ of total cells in the filaments. Principal components for vegetative cells varied significantly between growth conditions. These results agree with the fact that vegetative cells are responsible for uptake of carbon and energy, and for the generation of reductant, and with the fact that carbon, energy, and reductant are the parameters that vary between

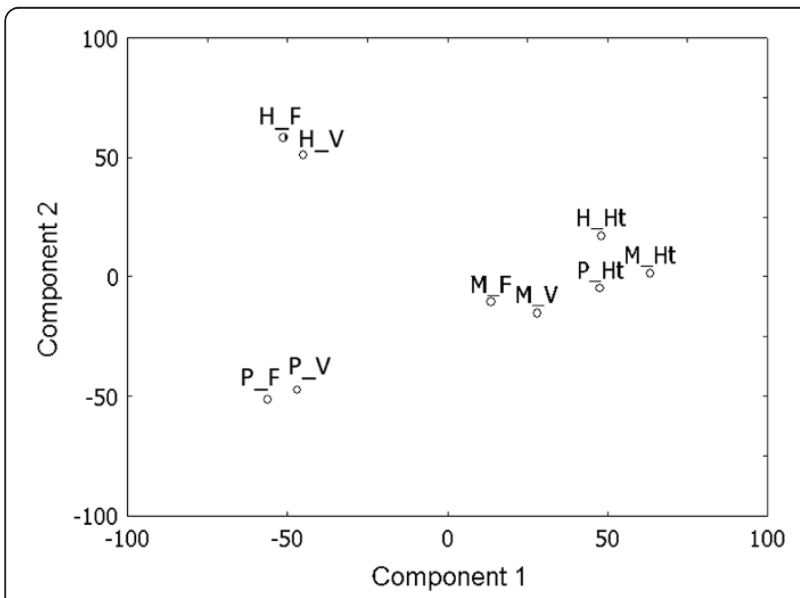

Figure 3 Principal component analysis of gene expression patterns in different cell types and different growth conditions. Component 1 is plotted versus component 2. PCA was performed using the entire normalized data set of 5,657 genes. F: whole filaments; $\mathrm{H}$ : heterotrophic conditions; Ht: heterocysts; M: mixotrophic conditions; P: phototrophic conditions; and V: vegetative cells. growth conditions. In contrast, principal components for heterocysts varied little between growth conditions. Heterocysts are consistently responsible for nitrogen fixation. The lack of change of principal components for heterocysts in heterotrophic conditions suggests that access to light is not among the top determinants of transcript levels in heterocysts. The fact that heterocyst-specific PCA results (Figure 3) and volcano plots from phototrophic cultures (Additional file 2: Figure S2) are not clearly distinguishable from those of mixotrophic and heterotrophic cultures helps to validate our decision to use seemingly partially degraded heterocyst RNAs from phototrophic cultures for our microarray studies.

\section{Functional categorization of microarray data}

To determine which pathways are upregulated in the different growth conditions and in the different cell types, the 5,657 ORFs represented in the microarrays were classified in sixteen functional categories (Additional file 3). Fourteen categories were based on the Kyoto Encyclopedia of Genes and Genomes (KEGG) pathway database [48], Blastp searches [49], and previous publications of gene functions. ORFs annotated only with a protein domain name were arbitrarily included in the Other functions category and those annotated as hypothetical proteins or proteins of unknown function were arbitrarily grouped in the Unknown category. The Other and Unknown categories contained 1,802 and 2,201 genes, respectively (Additional file 3). Since filaments consist mostly of vegetative cells, distribution of transcript levels per functional category was highly similar in whole filaments and vegetative cells in each growth condition tested, as expected (Figure 4). Because sources of carbon and energy are the parameters that vary between growth conditions, the pathways that were upregulated in vegetative cells (and whole filaments) varied widely from one growth condition to another. In contrast, distribution of transcript levels in terms of functional category varied little in heterocysts across growth conditions, agreeing with the fact that heterocysts perform the same main metabolic function, $\mathrm{N}_{2}$ fixation across the three growth conditions (Figure 4). These results agree with our PCA results.

The genes involved in phycobilisome assembly, photosynthesis, and $\mathrm{CO}_{2}$ uptake/fixation were clearly upregulated in vegetative cells in phototrophic conditions. Transcript levels of these genes decreased in mixotrophic conditions, and even further in heterotrophic conditions, where all carbon and reducing power come from fructose. Genes involved in electron transfer and respiration were unexpectedly down-regulated in heterocysts across growth conditions. This observation does not support the common understanding that heterocysts actively respire [50,51] as a way to decrease intracellular $\mathrm{O}_{2}$ concentrations $[4,52,53]$. However, this 


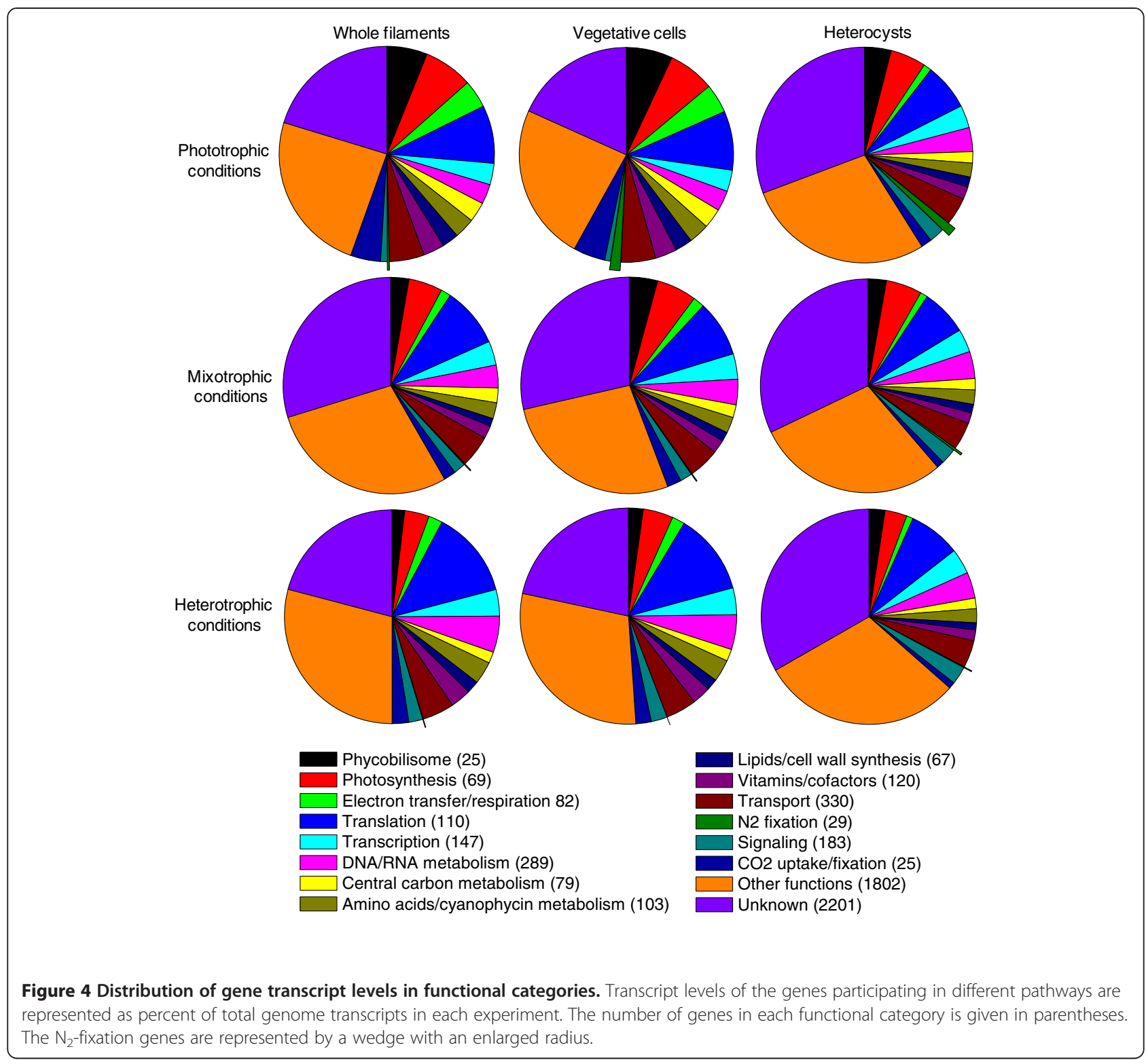

appears to be another instance in which, at least under heterotrophic conditions and for several oxidase subunits, the transcript level in heterocysts is likely underrepresented.

\section{Targeted analysis}

In this section our results will be described in terms of individual pathways, with a particular focus on pathways that we plan to study later by metabolic flux analysis (e.g., central carbon metabolism as well as nitrogen fixation and amino acid synthesis).

\section{Nitrogen fixation}

Of the three sets of nitrogenase genes (nif1, nif2, and $v n f$ ) present in A. variabilis, only the nif1 cluster is expected to be transcribed in aerobic $\mathrm{N}_{2}$-fixing cultures of $A$. variabilis grown in the presence of Mo [46,54-56]. Indeed, with the exception of nifH2 (Ava_4247) whose transcript level reached $1.5 \%$ of the most abundant transcript in the vegetative cells of phototrophic cultures, nif2 genes had background to very low transcript levels in all experiments (Additional file 7). Transcript levels of the $v n f$ genes were even lower than those of the nif 2 genes in all experiments. As expected, every gene in the nif 1 cluster was strongly upregulated in heterocysts of phototrophic and mixotrophic cultures (Additional file 7). In phototrophic conditions the upregulation of the nif1 genes in heterocysts ranged between 5.3-fold (nifU, Ava_3915) and 22-fold (nifB, Ava_3912), all with $\mathrm{p}<0.0001$. The nifH, nifD, and nifK signals in heterocysts reached $44 \%, 39 \%$, and $15 \%$ of 
the strongest signal in these cells, respectively. Ava_3940, encoding the ferredoxin FdxH1 that is believed to be the primary electron donor to nitrogenase [10], was also upregulated 15-fold in heterocysts of phototrophic cultures $(\mathrm{p} \sim 0.05)$.

Transcripts of nif1 genes are highly upregulated during the late stages of heterocyst differentiation [17,39] and their products appear to represent a large portion of the soluble protein of anoxically isolated heterocysts [2]. Nonetheless, transcripts of $\mathrm{N}_{2}$ fixation genes represented only $1.4 \%$ of total transcripts in heterocysts in phototrophic conditions, reflecting a likely 10-fold or greater underestimate of transcript levels of nif1 genes in these cells. It remains possible that RNAlater has difficulty traversing the barrier represented by the heterocyst envelope, so that nif1 transcripts (and likely other transcripts; see below) were extensively degraded. Because of microarray normalization, highly stable transcripts are likely over-represented in the heterocyst transcriptome.

The nif1 genes were also upregulated in heterocysts in mixotrophic conditions-between 1.6-fold (nifU) and 6.9fold (nifS, Ava_3914), with p values between 0.01 and 0.05-but not to the same extent as in phototrophic conditions. In heterotrophic conditions the nif1 genes were, at most, moderately upregulated in heterocysts, with $\mathrm{p}$ values never under 0.01 , and the nifD transcript reached only $2.3 \%$ of the highest heterocyst transcript. Several reasons could contribute, exclusively or in combination, to the low nif1 transcript levels in heterotrophic cultures: these cultures are energy-deprived compared to cultures grown in light, the nif1 RNAs might be partially degraded in our RNA preparations, and nitrogenase might be particularly stable in these conditions.

\section{Amino acid biosynthesis}

Whereas synthesis of Gln and Glu in $\mathrm{N}_{2}$-fixing filaments has been the focus of many studies because they are responsible for ammonia assimilation after $\mathrm{N}_{2}$ fixation, where and how the other amino acids are synthesized have not been looked at in much detail. Starting from the amino acid biosynthetic genes identified in $A$. variabilis in the KEGG database $[57,58]$, Blastp comparisons were used to verify all annotations and to identify which pathways are active. Not all pathways and genes could be identified with certainty, in particular enzymes involved in amination (i.e., Asn synthetase) and transamination reactions. The pathways shown in Figure 5 (extra comments in Additional file 8) and Additional file 7 represent the predominant amino acid biosynthetic pathways in A. variabilis based on the KEGG database, pathways that are common in the bacterial world $[59,60]$, known amino acid synthesis pathways in cyanobacteria, and pathways supported by earlier isotope labeling studies.
Amino acid biosynthetic genes were typically either upregulated in vegetative cells or transcribed at similar levels in the two cell types (Figure 5). Only select genes appeared upregulated in heterocysts (e.g., Ava_1668, with $\mathrm{p} \leq 0.05$ ) (Figure 5). A few instances were found in which multiple genes encoding isozymes showed different transcript patterns. Most amino acid biosynthetic genes are not organized in operons in $A$. variabilis, so one gene can be transcribed at a very low level, while all other genes in the pathway are transcribed at significant levels. Several genes showed background level transcripts across experiments, possibly due to mRNA instability, making it impossible to predict in which cell type these genes are transcribed (Figure 5). Using a signal intensity cutoff of 200 as the minimum, transcript levels in heterocysts plus the phosphoserine phosphatase activity detected in the crude extracts of heterocysts of phototrophic cultures (footnote f of Figure 5) suggest that Gln, Glu, Ser, Gly, Cys, Thr, and Pro are actively produced in heterocysts. Whether or not the other protein amino acids are actively synthesized in heterocysts is unclear based on our data, because of genes not identified or of transcript levels below 200 SIU for some genes in a given pathway (Figure 5).

The breakdown of phycobiliproteins in heterocysts has been studied as a possible major source of amino acids for de novo protein synthesis in heterocysts $[61,62]$. All phycobiliprotein-encoding genes were still transcribed at significant levels in the heterocysts of phototrophic cultures (Figure 6). nblA (Ava_3383), encoding a protein required for the breakdown of phycobiliproteins was upregulated 2.2 -fold $(\mathrm{p}<0.01)$ in the heterocysts of phototrophic cultures, but not in other growth conditions. The alanine dehydrogenase gene Ava_0176, required for the breakdown of phycobiliproteins in Synechococcus PCC 7942 [63], was downregulated in heterocysts across growth conditions. These collective results suggest that while the breakdown of phycobiliproteins may contribute much of the amino acids needed during heterocyst differentiation, it may contribute little to protein repair and protein de novo synthesis in mature heterocysts. This conclusion is consistent with labeling experiments that showed that newly forming and mature heterocysts of $A$. oscillarioides incorporated significant levels of ${ }^{13} \mathrm{C}$ and ${ }^{15} \mathrm{~N}$ in cultures grown with $\mathrm{NaH}^{13} \mathrm{CO}_{3}$ and ${ }^{15} \mathrm{~N}_{2}$ [64].

\section{Transport of amino acids and other metabolites}

Three PCC 7120 ATP-binding cassette (ABC) transporters specific for amino acids have been characterized: two neutral amino acid transporters, N-I and N-II, and a basic amino acid transporter, Bgt. Both N-I (composed of NatABCDE) and N-II (composed of NatFGH and BgtA) contribute to diazotrophic growth (Gln is a substrate for 
both transporters), but Bgt is not required [65-68]. In our work, nat $A$ and nat $G$ had background transcript levels in all conditions. The other N-I and N-II genes had transcript levels reaching $0.25 \%$ to $5.7 \%$ of the highest transcripts (Additional file 7). The single Bgtspecific gene, $\operatorname{bgt} B$, had background-level signal intensities across all experiments (Additional file 7). Recent studies suggest that the septosome (formerly microplasmodesmata) allows passive diffusion of molecules up to $623 \mathrm{Da}$, and that SepJ, FraC, and FraD are involved in transport via the septosome [69-71]. While the sepJ and fraD transcripts were detected across all experiments $(s e p J)$ and in vegetative cells only (fraD), the fra $C$ transcript was barely detectable in any condition (Additional file 7). Background transcript levels for some of these genes (e.g., natA, natG, and fraC) might reflect low abundance and/or high stability of these proteins in vivo.

\section{Photosystems}

In heterocyst-forming cyanobacteria, vegetative cells express both PS I and PS II; they use water as the electron donor and produce $\mathrm{O}_{2}$. Heterocysts use PS I to generate ATP [72]. Transcript levels of eighteen PS I-related genes (Figure 6 and Additional file 7) were compared in all experiments. psaA-E, psaJ-K, and $y c f 37$ showed no significant difference in signal intensity between heterocysts and vegetative cells across growth conditions. $p s a F, L$, and $X$, as well as $y c f 3, y c f 4$, and $b p t A$ were upregulated 2- to 3fold in vegetative cells $(\mathrm{p}<0.01)$, some of them only in phototrophic conditions. These five genes encode proteins involved in PS I docking (PsaF), PS I oligomerization (PsaL), PS I assembly (Ycf3 and 4), or have an unknown function (BptA). Why some PS I genes are more upregulated than others may relate to a different ratio of ATP to reduced ferredoxin needed for the different metabolic processes in heterocysts and vegetative cells. 


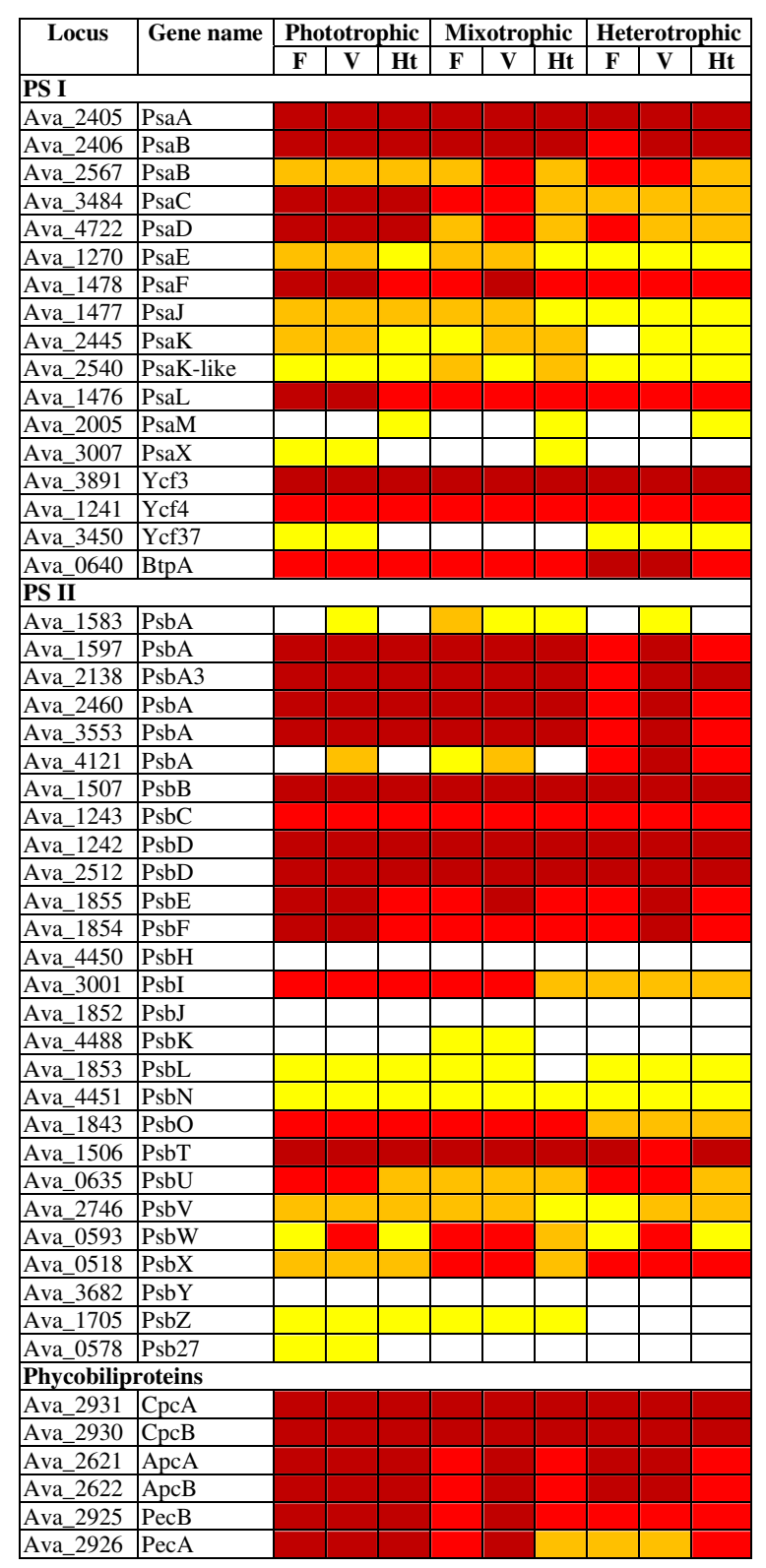

Figure 6 Transcripts of genes encoding PS I, PS II, and phycobiliproteins. Colors are as in Figure 5.

PS II-and, in particular, its protein PsbA-is prone to oxidative damage [73,74]. The main response in cyanobacteria is transcriptional: specific $p s b A$ genes are upregulated. In steady state conditions, PsbA1 is the most abundant PsbA protein in PS II, and its transcript-typically not upregulated in stress conditions-is the most abundant psbA transcript [73]. Accordingly, the transcript level for Ava_2138 (psbA1) was the most abundant psbA transcript in filaments of phototrophic cultures, with similar levels in vegetative cells. Other $p s b A$ genes showed higher transcript levels in vegetative cells than in filaments, most conspicuously under heterotrophic conditions (Additional file 7). These results suggest that the cavitation used to lyse vegetative cells causes oxidative stress that upregulates transcript levels of certain $p s b A$ genes. $p s b W$ behaves similarly, suggesting that it, too, may be involved in PS II repair.

Heterocysts were long thought to have no PS II and to lack the ability to evolve $\mathrm{O}_{2}$ [75-77]. Our results (Figure 6 and Additional file 7) support recent proteomic 
observations that find PS II proteins in heterocysts [26-28,78]. In particular, four of the six $p s b A$ genes, $p s b B$, $p s b C$, and the two $p s b D$ genes showed similar signal intensity levels in vegetative cells and heterocysts across growth conditions. The transcripts of psbA3, psbD (Ava_1242), and $p s b B$ even reached $70 \%$ to $92 \%$ of the most abundant heterocyst transcripts in phototrophic and mixotrophic cultures. This observation suggests that $p s b$ transcripts are not just inherited from a pre-heterocyst cell, but are actively produced in mature heterocysts as well. Other $p s b$ genes tended to have higher signal intensities in vegetative cells, but-with the exception of $p s b H, p s b$, and $p s b Y$ that had background transcript levels in all experiments-were usually still transcribed in heterocysts. PsbO, U, and V, which stabilize the $\mathrm{O}_{2}$-evolving complex [79], had transcripts upregulated between 1.9- and 2.7-fold ( $<<0.02$ ) in vegetative cells of phototrophic cultures, but were still transcribed in heterocysts across growth conditions (Figure 6).

\section{Photosynthetic pigments}

Fewer phycobilisomes, the main light-harvesting complexes for PS II in the vegetative cells [75], could account for a diminution of $\mathrm{O}_{2}$-evolving activity of PS II in heterocysts. Spectrophotometric studies suggest that heterocysts contain almost no allophycocyanin, that their low phycocyanin content varies with light intensity, and that their phycobiliproteins may transfer light energy to PS I [76,80]. Transcripts for the $A$. variabilis phycocyanin genes, $\operatorname{cpc} A B$, were found to be over 20-fold more abundant in vegetative cells than in heterocysts $16 \mathrm{~h}$ after nitrogen step-down [81]. Transcript levels for all phycobiliprotein genes in heterocysts of phototrophic cultures were much higher in our experiments than expected from previous studies. Signal intensities for $c p c A B$, $a p c A B$, and pec $A B$ in heterocysts were $80 \%, 33 \%$, and $35 \%$ to $45 \%$ of those in vegetative cells, respectively (all with $\mathrm{p}<0.058$ ) (Figure 6 and Additional file 7). Signal intensities for $c p c A B$ remained very high in vegetative cells and heterocysts of mixotrophic cultures, while transcript levels of $a p c A B$ and pecAB decreased over 6fold in mixotrophic conditions.

Ten chlorophyll biosynthetic genes were upregulated in vegetative cells of phototrophic cultures, although not all in a statistically significant manner (Additional file 7). Ava_4393, encoding one of three coproporphyrinogen oxidases, stood apart, being upregulated 3.8- to 5.1-fold in heterocysts across growth conditions $(\mathrm{p} \leq 0.03)$. This oxidase may participate in heme synthesis. Twelve chlorophyll biosynthetic genes were downregulated at least 2.5-fold in the filaments of mixotrophic cultures compared to phototrophic conditions, with the first dedicated gene in the pathway (Ava_3699, encoding glutamyl-tRNA reductase) downregulated 19-fold.

\section{$\mathrm{CO}_{2}$ fixation}

In cyanobacteria, ribulose-1,5-bisphosphate carboxylase oxygenase (RuBisCO) is often concentrated in subcompartments-the carboxysomes-in which $\mathrm{CO}_{2}$ is concentrated to high levels by a carboxysome-specific carbonic anhydrase [82-84]. Transcript levels of the genes encoding the high-affinity bicarbonate $\mathrm{ABC}$ transporter $\mathrm{CmpABCD}$ reflect the varying cellular need for $\mathrm{CO}_{2}$ in the three growth conditions (Figure 7). Most carboxysome-related transcripts were significantly more abundant in the vegetative cells than in the heterocysts of phototrophic cultures (Figure 7). The abundant transcripts detected for most carboxysomal genes in heterocysts could have been produced in vegetative cells or proheterocysts (immature heterocysts) prior to their differentiation into heterocysts or could have been synthesized in the heterocysts. CcmK1, CcmK2, and CcmM are present at significant levels in the heterocysts of PCC 7120 [26]. The carbonic anhydrase encoded by Ava_2165 is similar to CcaA, the carboxysome-specific carbonic anhydrase in many cyanobacteria, but Ava_2165 was transcribed at background level across experiments. Most Calvin cycle genes were upregulated in the vegetative cells of phototrophic cultures. They were transcribed at significant levels across most experiments, with the exception of Ava_3290, encoding triosephosphate isomerase, whose transcript levels were very low or not distinguishable from background (Figure 7 and Additional file 7).

\section{Central carbon metabolism}

Most genes encoding glycolysis, pentose phosphate pathway, and tricarboxylic acid cycle enzymes had moderate to high transcript levels across experiments (Additional file 7). Ten of nineteen glycolysis genes, the three known oxidative pentose phosphate pathway genes, and seven of ten genes in the tricarboxylic acid cycle were upregulated 1.5- to 7.4-fold ( $\mathrm{p} \leq 0.05)$ in the vegetative cells of phototrophic cultures (Additional file 7). The same genes were not consistently upregulated in the vegetative cells of mixotrophic or heterotrophic cultures. Ava_1682 and Ava_1683 encode, respectively, the oxidative pentose phosphate cycle proteins, glucose-6phosphate dehydrogenase (G6PD) and OpcA. In $N$. punctiforme, OpcA appears to be an allosteric activator of G6PD and to affect redox modulation of G6PD [85]. The transcript of $z w f$ (encoding G6PD) in N. punctiforme accumulated $42 \mathrm{~h}$ after nitrogen stepdown [86]. In $A$. cylindrica Lemm., the G6PD activity level in heterocysts was estimated to be 67 -fold higher than in vegetative cells [87]. Under mixotrophic conditions, transcript levels of Ava_1682 and Ava_1683 were significantly higher in filaments than in vegetative cells and significantly higher in vegetative cells than in heterocysts. These observations suggest that-at least under mixotrophic 


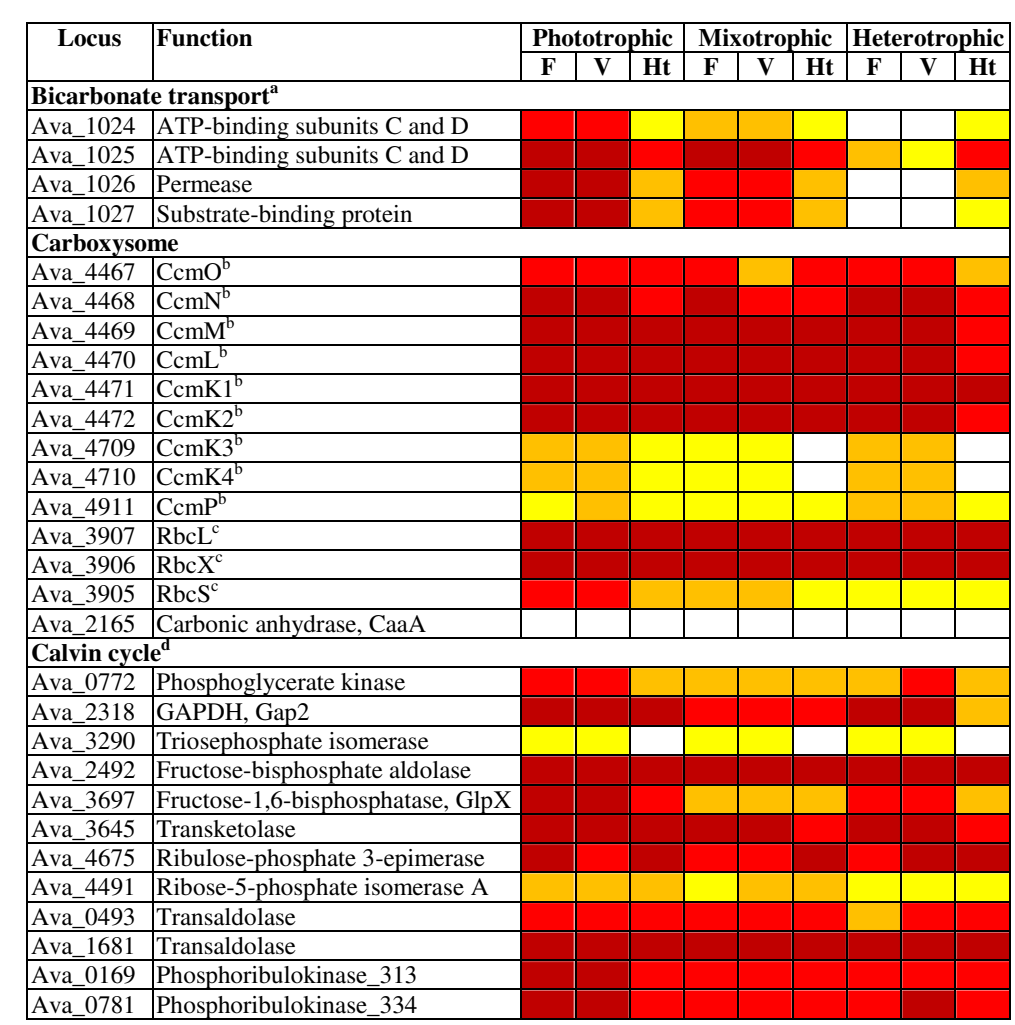

Figure 7 Transcripts of $\mathrm{CO}_{2}$-fixation genes. Colors are as in Figure 5. Legends for superscripts "a" to "d" are in Additional file 8.

conditions-transcripts of Ava_1682 and Ava_1683 may be under-represented in heterocysts. Transcript levels of Ava_3044 (encoding 6-phosphofructokinase) were just above background level across cell types in phototrophic and mixotrophic conditions, but were high across cell types in heterotrophic conditions. A. variabilis has three glyceraldehyde-3-phosphate dehydrogenases, Gap1, Gap2, and Gap3. The gap2 transcript was abundant across all experiments, in particular in phototrophic conditions, where it reached $47 \%$ of the most abundant transcript in vegetative cells (Figure 7 and Additional file 7, Calvin cycle). This observation is similar to a previous finding that Synechocystis PCC 6803 Gap2 is present in multiple growth conditions, with maximum activity in photoautotrophic conditions [88]. Downregulation of gap2 in heterocysts (Figure 7) also supports a previous report that Gap2 is less abundant in heterocysts than in vegetative cells of $A$. variabilis [89]. However, whereas Valverde et al. [89] detected gap3 transcripts in heterocysts and vegetative cells of $A$. variabilis, but none of gap1, we found the opposite (Additional file 7).

\section{Sucrose metabolism}

Sucrose is thought to be the principal form of reduced carbon transferred to heterocysts during diazotrophic growth [4,8,9,90-92]. In cyanobacteria sucrose is synthesized by sucrose-phosphate (sucrose-P) synthase and sucrose-P phosphatase $[93,94]$. PCC 7120 sucrose-P synthases SpsA and SpsB have different specificities for UDP- and ADP-glucose [93]. In PCC 7120 SpsA is expressed only in vegetative cells and $\mathrm{Sps} B$ is expressed in all cells [95]. In our phototrophic cultures, sps $A$ was upregulated 6-fold in vegetative cells $(\mathrm{p} \sim 0.096)$, in agreement with [95], but it was still transcribed at a low level in heterocysts. In mixotrophic and heterotrophic cultures, sps $A$ transcript levels in vegetative cells decreased 31-fold and 14.7-fold, respectively, to a level similar to that in heterocysts (Additional file 7). These observations suggest that sps $A$ expression is controlled, at least in part, by the carbon source. In contrast to $s p s A, s p s B$ was upregulated 5.6-fold, 1.9-fold, and 35-fold in the heterocysts of phototrophic, mixotrophic, and heterotrophic cultures $(\mathrm{p}<0.04)$, respectively. The sucrose-P phosphatase gene, $\operatorname{spp} A$ (Ava_2821), was transcribed at low levels across experiments, with a $\sim 2$-fold upregulation $(\mathrm{p} \leq 0.05)$ in the vegetative cells of phototrophic and mixotrophic cultures (Additional file 7).

Sucrose can be cleaved by invertases, which hydrolyze sucrose irreversibly to fructose and glucose [96], and by sucrose synthases. Sucrose synthases cleave sucrose with 
UDP in a reversible reaction. Inactivation of the invertase gene, $i n v B$, whose product is normally strongly expressed in heterocysts, greatly impaired PCC 7120's growth on $\mathrm{N}_{2}$ $[8,9]$. This result strongly supports the theory that sucrose is the main form of reduced carbon transferred to heterocysts during growth on $\mathrm{N}_{2}$. A second alkaline invertase, InvA, which is expressed at a low level in heterocysts, had no such mutant phenotype $[8,9]$. A variabilis has a single-neutral-invertase, InvB (Ava_0609). Transcript levels of $i n v B$ were just above background in heterocysts across growth conditions (Additional file 7).

As in related species, $A$. variabilis contains two sucrose synthases, Ava_2283 (SusA) and Ava_3753 (SusB). Curatti et al. $[91,97,98]$ suggested that SusA is involved in the conversion of sucrose to polysaccharides in heterocystforming cyanobacteria, matching a presumptive function of sucrose synthase in plants [99]. In our experiments, sus $A$ transcript levels were similar in heterocysts and vegetative cells of phototrophic cultures. While susA was upregulated 3.4-fold and 1.9-fold in the vegetative cells of mixotrophic and heterotrophic cultures, respectively, it was still transcribed at $2 \%$ to $2.6 \%$ of the most highly expressed genes in heterocysts in all conditions. sus A was also upregulated more than 5-fold in the filaments of mixotrophic cultures compared to phototrophic cultures, as observed by others [91,97,98] (Additional file 7). To our surprise, susB's transcript levels reached $18 \%$ to $24 \%$ of the most highly expressed genes in heterocysts across growth conditions. susB's transcript was 8.1 - to 9.6-fold more abundant than that of sus $A$ in heterocysts of all cultures (Additional file 7), suggesting that $s u s B$ may have different functions in $A$. variabilis and in Anabaena sp. PCC 7119. In PCC 7119, a susB mutant had no effect on growth or sucrose production [91], whereas a sus $A$ mutant accumulated more sucrose and less glycogen than the wild-type strain in $\mathrm{N}_{2}$-fixing conditions $[91,97,98]$.

The A. variabilis genome encodes at least two carbohydrate uptake transport (CUT) 1-family $\mathrm{ABC}$ transporters, which are specific for disaccharides and oligosaccharides. Among the twelve CUT1-related genes that were identified (Additional file 7), Ava_2748 and Ava_2050 were distinctive. Ava_2748 (membrane protein 2) was upregulated 7- to 31 -fold in heterocysts across growth conditions ( $\mathrm{p} \leq 0.036$ ), and Ava_2050 (ATP-binding protein) was upregulated 7- and 97-fold in heterocysts of phototrophic and heterotrophic cultures, respectively. In all growth conditions, Ava_2050 signal intensities in heterocysts reached at least $26 \%$ of that of the most transcribed genes in those cells. These two proteins could be part of an ABC transporter responsible for sucrose uptake in heterocysts. The remaining components of this hypothetical sucrose transporter (i.e., the membrane protein 1 and the substrate-binding protein) cannot be identified with reference only to $A$. variabilis based on our data, because the CUT1-related genes are not clustered in the $A$. variabilis genome. However, the orthologs of Ava_2748 in N. punctiforme (Npun_R2792) and Anabaena 90 (Ana_C20533) are adjacent to genes Npun_R2793 and Ana_C20534, both of which are orthologs of Ava_0461, annotated as membrane protein 1 in a CUT1 transporter (Additional file 7). Our results show that Ava_0461 is also strongly up-regulated in heterocysts, at least in phototrophic (F, V, Ht: $46 \pm 3,57 \pm 15,187 \pm 23$ SIU) and heterotrophic conditions (F, V, Ht: $44 \pm 6,49 \pm 3 ; 250 \pm 47$ SIU). In addition, Ana_C20533 and Ana_C20534 are clustered with Ana_C20535, which is annotated as the periplasmic component of an ABC-type sugar transport system.

\section{Glycogen metabolism}

The genes for glycogen synthesis enzymes ADP-glucose pyrophosphorylase (Ava_2020), glycogen synthase 1 (Ava_2631), glycogen synthase 2 (Ava_4775), and glycogen branching enzyme (Ava_4616) were upregulated 2.9- to 6.4-fold in the vegetative cells of phototrophic cultures $(\mathrm{p} \leq 0.054)$. The four genes were downregulated in mixotrophic conditions, with transcript levels in filaments 3.6- to 6.3-fold lower in mixotrophic than phototrophic conditions $(\mathrm{p} \leq 0.022)$ (Additional file 7$)$. This last result seems to disagree with an earlier study that showed that mixotrophically-grown filaments contain more glycogen than phototrophically-grown filaments [100]. That early study used $40 \mathrm{mM}$ fructose in the medium, whereas we used only $5 \mathrm{mM}$ fructose. One possible explanation is that a higher supply of fructose and nucleotide sugars improves the kinetics of glycogen synthesis and decreases the need for more enzyme production.

The two genes encoding glycogen phosphorylases (Ava_2996 and Ava_1084) were, as a rule, upregulated in vegetative cells $(0.002 \leq \mathrm{p} \leq 0.06)$, and slightly upregulated in phototrophic vs. mixotrophic and heterotrophic conditions. In contrast, the debranching enzyme (Ava_2025) gene did not show a cell-specific transcript pattern. The two genes encoding $\alpha$-phosphoglucomutases (Ava_1737 and Ava_2367) were upregulated over 2.4-fold in the vegetative cells of phototrophic cultures $(p \leq 0.05)$ and were upregulated up to 3.4-fold in phototrophic vs. mixotrophic and heterotrophic conditions (Additional file 7).

\section{Development-related genes}

The heterocyst differentiation genes with the highest signal intensities included $\operatorname{devH}(32 \%$ to $60 \%$ of the most transcribed gene), sepJ (9\% to $17 \%$ ), hetR ( $4 \%$ to $26 \%$ ), $h g l K$ (4\% to $17 \%), n t c A$ ( $2.8 \%$ to $6.1 \%), p b p C$ (1.6\% to $13.5 \%)$, nrrA (2\% to $10 \%)$ and hetN (1.3\% to $8 \%)$. Transcript levels for het $C$, hetF, het $L$, hetP, patA, patB, patS, hep $A$, hep $B$, $h e p K, \operatorname{dev} C, \operatorname{dev} R, p k n 30$, and $h g d A$ reached at most 
$2.5 \%$ of the most transcribed gene in all experiments (Additional file 7). A clear illustration of the fact that most heterocysts in our steady-state cultures are mature rather than developing heterocysts is the 7 - to 25 -fold downregulation $(\mathrm{p}<0.01)$ of genes involved in the formation of the heterocyst envelope polysaccharide (hepA, Ava_1106, Ava_1108, Ava_1114, Ava_1116, Ava_1120, Ava_1122, and Ava_1124) [13,101] and of the heterocystspecific glycolipid layer $\left(h g d B, h g d C, h g l A, h g l E_{A}\right.$, and $h g l G)$ [13] in the heterocysts of phototrophic cultures (Additional file 7).

\section{Genes whose functions have not been characterized experimentally}

Many uncharacterized genes were upregulated in heterocysts in at least two growth conditions (Additional file 9). Most of the uncharacterized genes strongly upregulated in heterocysts in phototrophic and heterotrophic conditions did not appear to be upregulated in the heterocysts of mixotrophic cultures. Still, uncharacterized genes that were the most upregulated in heterocysts showed remarkably similar transcript levels in heterocysts across growth conditions (Additional file 9), suggesting that upregulation of these genes in heterocysts is real.

In contrast to the uncharacterized genes upregulated in heterocysts, most uncharacterized genes that were strongly upregulated in vegetative cells were upregulated in a single growth condition (Additional file 9). This observation may be related to our PCA results-growth conditions affected parts of the carbon and energy metabolisms in vegetative cells. Groups of contiguous genes Ava_2383-2385 and Ava_4373-4375 that were transcribed only in vegetative cells and only in phototrophic conditions, and show no similarity to each other, merit note. Those groups encode 80 -residue proteins that are $70 \%$ to $96 \%$ identical to each other, and are found only in a subset of heterocyst-forming cyanobacteria. The transcript level of Ava_2384 reached close to 20\% of the most abundant transcript in vegetative cells (Additional file 9).

\section{Discussion}

We report the first comparison of gene expression patterns in the vegetative cells and heterocysts of a filamentous cyanobacterium, A. variabilis ATCC 29413. RT-qPCR results showing mean upregulation levels no greater than 14.5 -fold for $r b c L$ in vegetative cells and no greater than 9.9-fold for nifK in heterocysts suggested initially that our RNA extractions were not adequately cell-specific. Cell specificity of our vegetative cell RNA extracts was obscured by the facts that the $r b c L$ transcript in heterocysts reached up to $33 \%$ of the most transcribed ORF in heterocysts, and that $r b c L$ was transcribed at lower levels in vegetative cells under heterotrophic and mixotrophic conditions than under phototrophic conditions. Cell specificity of our heterocyst RNA preparations was obscured by the fact that nif1 transcripts were apparently targeted for rapid degradation during our isolation of heterocysts. Although substantial transcript levels of $r b c L$ in heterocysts are inconsistent with imaging of transcriptional fusions of $r b c L$ to luciferase in PCC 7120, which showed at most very slight expression in heterocysts compared to vegetative cells [39], and with diverse other data [4], A. variabilis heterocysts might use RuBisCO to reassimilate $\mathrm{CO}_{2}$ released by the oxidative pentose phosphate pathway $[87,102]$.

Still, our microarray results suggest that RNA preparations from heterotrophic cultures were over 90\% cellspecific, with eighteen genes upregulated between 10- and 19-fold in vegetative cells and thirty-five genes upregulated between 30- and 167-fold in heterocysts. Similarly, transcript levels of Ava_4669 and Ava_2050 were over 200fold higher in the heterocysts than in the filaments of phototrophic cultures (Additional file 9). At least one gene, Ava_2687 (encoding an arsenate reductase-related protein), was strongly upregulated in heterocysts across growth conditions (60-, 24-, and 58-fold in phototrophic, mixotrophic, and heterotrophic cultures, respectively). This gene could be used as an alternative probe to nifK to determine the cell specificity of heterocyst RNA extractions. In contrast, we found no gene that would be a consistently strong, specific probe for vegetative cell RNA extracts across the three tested growth conditions. Because genes highly upregulated in vegetative cells were in no instance highly upregulated in all three growth conditions, a more reliable approach for future studies will likely be to use different RT-qPCR probes for vegetative cells for different conditions, e.g., Ava_2383 for phototrophic conditions, Ava_2928 for mixotrophic conditions, and Ava_3729 for heterotrophic conditions.

\section{Development-related genes and certain uncharacterized genes}

Our analysis was not expected to illuminate the process of heterocyst differentiation, per se, for three interrelated reasons: (i) Steady state cultures were needed for prospective metabolic flux analysis. (ii) RNA extracted from vegetative cells in steady state cultures is combined with RNA extracted from proheterocysts that have not yet formed the envelope that protects against cavitation. Presumably as a result, genes involved in early, transient developmental processes such as deposition of the heterocyst envelope appear upregulated in vegetative cells (Additional file 7). (iii) Correspondingly, RNA is isolated from mature or almost fully mature heterocysts only when their envelope protects them extensively against cavitation. Therefore, our analysis provides the opportunity to highlight ongoing processes characteristic of mature heterocysts, including their interactions with vegetative 
cells, and to gain further insight into the physiological differences between mature heterocysts and vegetative cells. To those ends, we have provided (in Additional file 7) a section on known heterocyst developmental genes and (in Additional file 9) sections on differentially transcribed genes. Among these genes are Ava_2748 and Ava_2050, which are likely parts of one or two carbohydrate uptake transport (CUT) 1-family $\mathrm{ABC}$ transporters, known to be specific for di- and oligosaccharides. These two genes represent possible members of the yet unknown sucrose transporter. Although we recognize that under phototrophic conditions, transcript levels in heterocysts are inflated because of the low nif 1 transcript levels, the 204-fold and 35-fold higher transcript levels for Ava_2050 and Ava_2748, respectively, in heterocysts than in filaments still suggest that these genes are upregulated in heterocysts in these conditions. Other genes from Additional file 9 that have high transcript levels, and are strongly upregulated, in heterocysts may also warrant inquiry.

Under phototrophic conditions, 77\% of the genes with unknown products that were upregulated in one type of cell versus the other were upregulated in heterocysts. Despite the limitations of our data (e.g., degradation of the nif1 transcripts), these observations suggest to us that much of what is unknown about the metabolism of phototrophic, $\mathrm{N}_{2}$-fixing cultures takes place in heterocysts.

\section{Amino acid biosynthesis}

The current model for nitrogen assimilation after $\mathrm{N}_{2}$ fixation has $\mathrm{NH}_{3}$ incorporated into Gln by glutamine synthetase (encoded by $g \ln A$ ) in heterocysts $[6,17]$. Gln is then transported to vegetative cells, where-together with 2-oxoglutarate-it serves as substrate for glutamate synthase (encoded by $g l s F$ ) to produce two Glu $[6,7,103]$. Finally, one Glu is transported back to the heterocysts, where it becomes the substrate of glutamine synthetase for Gln synthesis. The Gln-Glu exchange between vegetative cells and heterocysts results in a net nitrogen flux to the vegetative cells. The second glutamate synthase substrate, 2-oxoglutarate, may also be produced in heterocysts by isocitrate dehydrogenase $[7,104]$. In PCC 7120 , glutamine synthetase activity is regulated by protein-protein interactions with the inhibitory protein IF7 (encoded by gifA), whose expression is negatively controlled by NtcA [105]. In A. variabilis, IF7 is encoded by Ava_0148, adjacent to $g \ln A$. Glutamate dehydrogenase (encoded by $g d h A$ ) does not seem to play an important role in nitrogen assimilation $[103,106]$, but it can give a competitive advantage in nonexponential phases of growth, possibly related to the fact that ATP is not required for its activity [107]. Other authors [108] suggest that Arg may be an alternative carrier of fixed nitrogen from heterocysts.

Prior results [6,39] with A. cylindrica and PCC 7120 led to the expectation that under photoautotrophic conditions, glutamine synthetase would be active in both types of cells whereas glutamate synthase would be active specifically in vegetative cells. However, in A. variabilis, glutamine synthetase, glutamate synthase, and isocitrate dehydrogenase appear to be actively transcribed in both types of cells. Our results therefore suggest that Glu and Gln, as well as Ser, Gly, Cys, Thr, and Pro, are actively produced in heterocysts. For all other protein amino acids, our results are inconclusive. The phenotypes of several amino acid $\mathrm{ABC}$ transporter mutants of PCC 7120 are known [65-68], but molecules as large as 623-Da calcein may move back and forth passively between vegetative cells and heterocysts, perhaps through the septosome, without transiting through the periplasm $[69,70]$. Until it has been proven or disproven that amino acids are transported through the septosome, the phenotypes of amino acid $\mathrm{ABC}$ transporters cannot be used to help reach a conclusion that a particular amino acid is or is not synthesized in heterocysts.

It is not excluded that only certain steps of amino acid synthesis take place in heterocysts, with precursors being provided by vegetative cells. Because heterocysts funnel much of their energy and redox power into $\mathrm{N}_{2}$ fixation, some redox or energy-intensive enzymatic steps might take place only in vegetative cells. For example, the two genes in the Lys pathway that are transcribed at the lowest levels in heterocysts encode enzymes that require ATP (aspartate kinase) and $\mathrm{NAD}(\mathrm{P}) \mathrm{H}$ (dihydrodipicolinate reductase) (Figure 5). Future metabolic flux analyses with diazotrophically grown $A$. variabilis must test for the possible transport of Ala, Asn, Asp, Lys, Arg, Phe, Tyr, Trp, Ile, Val, Leu, His, and Met (or their precursors) between cell types.

\section{Photosynthesis}

In agreement with our results, peptides corresponding to PsbO, PsbU, and PsbV were detected in heterocysts of PCC 7120 at frequencies above $50 \%$ of those observed in vegetative cells (Table S4 in [26]). Even though PS II likely does not evolve $\mathrm{O}_{2}$ in heterocysts, our results support the hypothesis that complete or incomplete PS II complexes have an as yet unknown function in heterocysts. A cyclic electron flow could exist in heterocyst PS II [109], serving as a further source of ATP, and [4] an electron carrier (e.g., sulfide or ferrous ions) might shuttle electrons between vegetative cells and heterocyst PS II.

\section{$\mathrm{CO}_{2}$ fixation}

A. variabilis $\mathrm{CcmM}$ has an $\mathrm{N}$-terminal carbonic anhydrase domain followed by three RbcS-like domains. In Thermosynechococcus elongatus, which lacks a ccaA homo$\log , \mathrm{CcmM}$ is the carboxysomal carbonic anhydrase [84]. PCC 7120 and A. variabilis CcmM proteins contain all of the conserved residues thought to be required 
for T. elongatus CcmM carbonic anhydrase activity [84]. Because PCC 7120 lacks a ccaA homolog and because ccaA is barely transcribed in A. variabilis, CcmM-with high to very high transcript levels in vegetative cells-may be the carboxysome-specific carbonic anhydrase in PCC 7120 and A. variabilis. In Synechococcus PCC 7942, the average RuBisCO complex contains eight $\mathrm{RbcL}$ molecules and five $\mathrm{RbcS}$ molecules, and CcmM has been shown to form complexes readily with RbcL [110]. It is tempting to speculate that in vegetative cells of $A$. variabilis, CcmM assembles with incomplete RbcL-RbcS complexes to form a bi-functional RuBisCO-carbonic anhydrase. Such an assembly might permit efficient channeling of $\mathrm{CO}_{2}$ from carbonic anhydrase to RuBisCO. It would also explain why the $r b c S$ transcript was 13 -fold less abundant than the $r b c L$ transcript in the vegetative cells of phototrophic cultures (Figure 7).

\section{Conclusions}

Derived from RNAs purified after lengthy cell separation procedures, our microarray data cannot compare in quality and applicability with others generated with rapidly extracted, more intact RNAs. Despite this limitation, our results show that the carbon source or sources significantly affect transcription patterns in vegetative cells but not as much in heterocysts. This finding agrees with the respective functions of vegetative cells and heterocysts. Our results help to clarify which amino acids are actively produced in heterocysts, and which may require transport from cell to cell. We hope to use this information to build a filament-level metabolic network model for metabolic flux analyses. This first direct comparison of transcript levels in heterocysts and vegetative cells also allowed us to identify many uncharacterized genes that are differentially regulated in the two cell types and that warrant further characterization.

\section{Availability of supporting data}

The data set supporting the results of this article is available in the National Center for Biotechnology Information Gene Expression Omnibus database, at http://www.ncbi. nlm.nih.gov/geo/ under accession number GSE46076.

\section{Additional files}

Additional file 1: Gene-specific primers used for RT-qPCR. This table lists the primers used for RT-qPCR to test the cell specificity of RNA extractions. The $m p B$ gene was used as an internal control for data normalization. rbcL and nifK were used as a vegetative cell-specific gene and a heterocyst-specific gene, respectively. F: forward; R: reverse.

Additional file 2: Figure S1. Bioanalyzer analysis of RNA quality in RNA samples extracted from phototrophic (P), mixotrophic (M), and

heterotrophic $(\mathrm{H})$ cultures. The RNA samples prepared from filaments, vegetative cells, and heterocysts from the three growth conditions were analyzed on a Bioanalyzer prior to being used for microarray experiments.
Figure S2. Volcano plots of ratios of transcript levels in heterocysts divided by corresponding levels in vegetative cells in phototrophic (P), mixotrophic (M), and heterotrophic $(\mathrm{H})$ cultures. The variation in transcript levels is expressed as the $\log _{2}$ of the ratio of transcripts in heterocysts divided by transcripts in vegetative cells, and is plotted versus the statistical significance of the variation, expressed as $\log _{10}$ of the $p$-value. Two-fold expression changes and $p$-values of 0.01 are indicated by red lines.

Additional file 3: Normalized microarray data. This table lists the normalized microarray data for our twenty seven experiments, representing the three biological replicates of experiments performed with RNA extracted from whole filaments, vegetative cells, and isolated heterocysts from phototrophic cultures, as well as from mixotrophic and heterotrophic cultures. Each gene is identified by its microarray sequence ID, its locus number, its predicted function, and its functional category. Fourteen categories were based on the Kyoto Encyclopedia of Genes and Genomes (KEGG) pathway database [48], Blastp searches, and previous publications of gene functions. ORFs annotated only with a protein domain name were arbitrarily included in the Other functions category and those annotated as hypothetical proteins or proteins of unknown function were arbitrarily grouped in the Unknown category.

Additional file 4: $\mathrm{R}^{2}$ values between all pairs of microarray experiments. This table lists the coefficients of determination ( $R^{2}$ values) between the twenty seven experiments. $\mathrm{R}^{2}$ values show that reproducibility was high for biological replicates of the same RNA extractions. In boldface and highlighted in green: $\mathrm{R}^{2}$ values between biological replicates of identical RNA extractions. Highlighted in yellow: $\mathrm{R}^{2}$ values between heterocyst RNAs extracted from different culture conditions. BR: biological replicate.

Additional file 5: Reduced data and weighted residuals for phototrophic, mixotrophic, and heterotrophic conditions. Reduced data are the normalized data once genes described in Additional file 6 have been deleted. The reduced data sets contain 3,949 genes in phototrophic conditions, 3,885 genes in mixotrophic conditions, and 3,933 genes in heterotrophic conditions. The weighted residuals were calculated using equation 1 with the $a$ and $b$ values determined by linear regression (Additional file 6).

Additional file 6: Data reduction and linear modeling. Additional file 6 describes how data for genes that are not expressed and genes that show inconsistent transcript levels were removed from the normalized data. Additional file 6 also details the results of linear modeling of the transcript data in each growth condition as applied to the reduced data using the function $F_{i}=a V_{i}+b H t_{i}-1$, where $F_{i}, V_{i}$, and $\mathrm{Ht}_{\mathrm{i}}$ represent the means of gene i transcript levels in filaments, vegetative cells, and heterocysts, respectively; $a$ and $b$ are constants that reflect the relative abundance of vegetative cells and heterocysts in the filaments; and -1 is a term that forces the intercept to 0 .

Additional file 7: Genes discussed in this study. This table lists all genes discussed in the manuscript. Each gene is identified by its locus number, and its predicted function. Microarray data are reported as averages of the three biological replicates for each experiment.

Additional file 8: Supplementary legend for Figure 5. Supplementary legend for Figure 7.

Additional file 9: Top uncharacterized genes upregulated in heterocysts and in vegetative cells. This spreadsheet lists the uncharacterized genes with the highest upregulation in heterocysts and in vegetative cells in each growth condition, based on the ratio of transcript levels between vegetative cells and heterocysts. Each gene is represented by its locus number and its predicted function.

\section{Competing interests}

The authors do not have any financial or non-financial competing interests.

\section{Authors' contributions}

JJP participated in designing the experiments, did most of the experimental work, participated in the analysis and interpretation of the data, and was involved in drafting the manuscript. SLY participated in conceiving and designing the experiments, participated in the analysis and interpretation of 
the data, and was involved in revising the manuscript critically for important intellectual content. CPW was involved in conceiving and designing the experiments, participated in the analysis and interpretation of the data, and was involved in revising the manuscript critically for important intellectual content. CV was involved in conceiving and designing the experiments, participated in the analysis and interpretation of the data, drafted most of the manuscript, and participated in revising the manuscript critically for important intellectual content. All authors read and approved the final manuscript.

\section{Acknowledgments}

We thank Zhen Zhang from the MSU Statistics help desk for writing the script for linear modeling analysis in R, Maris Laivenieks for preparing crude extracts and measuring phosphoserine phosphatase activity, and Christopher B. Jambor for editing the manuscript. Most of the experimental work was supported by the Great Lakes Bioenergy Research Center (GLBRC), DOE BER Office of Science, United States Department of Energy grant DE-FC0207ER64494. Additional work after funding from GLBRC stopped was funded by Michigan State University startup funds (CV) and by the Chemical Sciences, Geosciences, and Biosciences Division, Office of Basic Energy Sciences, Office of Science, United States Department of Energy grant DOE FG02-91ER20021 for discussions and work on the manuscript (SLY and CPW).

\section{Author details}

${ }^{1}$ Great Lakes Bioenergy Research Center, Michigan State University, East Lansing, MI 48824, USA. ${ }^{2}$ Department of Microbiology \& Molecular Genetics, Michigan State University, East Lansing, MI 48824, USA. ${ }^{3}$ MSU-DOE Plant Research Laboratory, Michigan State University, East Lansing, MI 48824, USA. ${ }^{4}$ Department of Plant Biology, Michigan State University, East Lansing, MI 48824, USA. ${ }^{5}$ Department of Biochemistry \& Molecular Biology, Michigan State University, East Lansing, MI 48824, USA. ${ }^{6}$ Present address: Institute of Biological Chemistry, Washington State University, Pullman, WA 99164, USA.

Received: 21 April 2013 Accepted: 26 October 2013

Published: 5 November 2013

\section{References}

1. Thiel T: Genetic analysis of cyanobacteria. In The Molecular Biology of Cyanobacteria. Edited by Bryant DA. Dordrecht, NL: Kluwer Academic Publishers; 1994:581-611.

2. Peterson RB, Wolk CP: High recovery of nitrogenase activity and of ${ }^{55} \mathrm{Fe}$-labeled nitrogenase in heterocysts isolated from Anabaena variabilis. Proc Natl Acad Sci U S A 1978, 75:6271-6275.

3. Thiel T, Pratte BS: Effect on heterocyst differentiation of nitrogen fixation in vegetative cells of the cyanobacterium Anabaena variabilis ATCC 29413. J Bacteriol 2001, 183:280-286.

4. Wolk CP, Ernst A, Elhai J: Heterocyst metabolism and development. In The Molecular Biology of Cyanobacteria. Edited by Bryant DA. Dordrecht: Kluwer Academic Publishers; 1994:769-823.

5. Walsby AE: Cyanobacterial heterocysts: terminal pores proposed as sites of gas exchange. Trends Microbiol 2007, 15:340-349.

6. Thomas J, Meeks JC, Wolk CP, Shaffer PW, Austin SM: Formation of glutamine from ${ }^{13} \mathrm{~N}$-ammonia, ${ }^{13} \mathrm{~N}$-dinitrogen, and ${ }^{14} \mathrm{C}$-glutamate by heterocysts isolated from Anabaena cylindrica. J Bacteriol 1977, 129:1545-1555.

7. Martín-Figueroa E, Navarro F, Florencio FJ: The GS-GOGAT pathway is not operative in the heterocysts. Cloning and expression of $\mathrm{glsF}$ gene from the cyanobacterium Anabaena sp. PCC 7120. FEBS Lett 2000, 476:282-286.

8. López-Igual R, Flores E, Herrero A: Inactivation of a heterocyst-specific invertase indicates a principal role of sucrose catabolism in heterocysts of Anabaena sp. J Bacteriol 2010, 192:5526-5533.

9. Vargas WA, Nishi CN, Giarrocco LE, Salerno GL: Differential roles of alkaline/neutral invertases in Nostoc sp. PCC 7120: Inv-B isoform is essential for diazotrophic growth. Planta 2011, 233:153-162.

10. Razquin P, Schmitz S, Peleato ML, Fillat MF, Gómez-Moreno C, Böhme H: Differential activities of heterocyst ferredoxin, vegetative cell ferredoxin, and flavodoxin as electron carriers in nitrogen fixation and photosynthesis in Anabaena sp. Photosynth Res 1995, 43:35-40.

11. Muro-Pastor Ml, Reyes JC, Florencio FJ: Ammonium assimilation in cyanobacteria. Photosynth Res 2005, 83:135-150.
12. Thiel T: Nitrogen fixation in heterocyst-forming cyanobacteria. In Genetics and Regulation of Nitrogen Fixation in Free-Living Bacteria. Edited by Klipp W, Masepohl B, Gallon JR, Newton WE. Dordrecht: Kluwer Academic Publishers; 2004:73-110.

13. Nicolaisen K, Hahn A, Schleiff E: The cell wall in heterocyst formation by Anabaena sp. PCC 7120. J Basic Microbiol 2009, 49:5-24.

14. Kumar K, Mella-Herrera RA, Golden JW: Cyanobacterial heterocysts. Cold Spring Harb Perspect Biol 2009, 2:a000315.

15. Flores $\mathrm{E}$, Herrero $\mathrm{A}$ : Compartmentalized function through cell differentiation in filamentous cyanobacteria. Nat Rev Microbiol 2010, 8:39-50.

16. Zhao J, Wolk CP: Developmental biology of heterocysts, 2006. In Myxobacteria: Multicellularity and Differentiation. Edited by Whitworth DE. Washington D. C: ASM Press; 2008:397-418.

17. Xu X, Elhai J, Wolk CP: Transcriptional and developmental responses by Anabaena to deprivation of fixed nitrogen. In The Cyanobacteria: Molecular Biology, Genomics and Evolution. Edited by Herrero A, Flores E. Norwich, U.K: Caister Academic Press; 2008:383-422.

18. Meeks JC, Campbell EL, Summers ML, Wong FC: Cellular differentiation in the cyanobacterium Nostoc punctiforme. Arch Microbiol 2002, 178:395-403.

19. Zhang C-C, Laurent S, Sakr S, Peng L, Bédu S: Heterocyst differentiation and pattern formation in cyanobacteria: a chorus of signals. Mol Microbiol 2006, 59:367-375.

20. Ehira S, Ohmori M, Sato N: Genome-wide expression analysis of the responses to nitrogen deprivation in the heterocyst-forming cyanobacterium Anabaena sp. strain PCC 7120. DNA Res 2003, 10:97-113.

21. Ehira S, Ohmori M: NrrA, a nitrogen-responsive response regulator facilitates heterocyst development in the cyanobacterium Anabaena sp. strain PCC 7120. Mol Microbiol 2006, 59:1692-1703.

22. Campbell EL, Summers ML, Christman H, Martin ME, Meeks JC: Global gene expression patterns of Nostoc punctiforme in steady-state dinitrogengrown heterocyst-containing cultures and at single time points during the differentiation of akinetes and hormogonia. J Bacteriol 2007, 189:5247-5256.

23. Kushige $H$, Kugenuma $H$, Matsuoka M, Ehira S, Ohmori M, Iwasaki H: Genome-wide and heterocyst-specific circadian gene expression in the filamentous cyanobacterium Anabaena sp. strain PCC 7120. J Bacteriol 2013, 195:1276-1284.

24. Flaherty BL, Van Nieuwerburgh F, Head SR, Golden JW: Directional RNA deep sequencing sheds new light on the transcriptional response of Anabaena sp. strain PCC 7120 to combined-nitrogen deprivation. BMC Genomics 2011, 12:332

25. Mitschke J, Vioque A, Haas F, Hess WR, Muro-Pastor AM: Dynamics of transcriptional start site selection during nitrogen stress-induced cell differentiation in Anabaena sp. PCC7120. Proc Natl Acad Sci U S A 2011 108:20130-20135

26. OW SY, Cardona T, Taton A, Magnuson A, Lindblad P, Stensjö K, Wright PC Quantitative shotgun proteomics of enriched heterocysts from Nostoc sp. PCC 7120 using 8-plex isobaric peptide tags. J Proteome Res 2008, 7:1615-1628.

27. Ow SY, Noirel J, Cardona T, Taton A, Lindblad P, Stensjö K, Wright PC: Quantitative overview of $\mathrm{N}_{2}$ fixation in Nostoc punctiforme ATCC 29133 through cellular enrichments and iTRAQ shotgun proteomics. J Proteome Res 2009, 8:187-198.

28. Cardona T, Battchikova N, Zhang P, Stensjö K, Aro E-M, Lindblad P, Magnuson A: Electron transfer protein complexes in the thylakoid membranes of heterocysts from the cyanobacterium Nostoc punctiforme. Biochim Biophys Acta 2009, 1787:252-263.

29. Wiechert W, Mollney M, Petersen S, de Graaf AA: A universal framework for ${ }^{13} \mathrm{C}$ metabolic flux analysis. Metab Engin 2001, 3:265-283.

30. Ratcliffe RG, Shachar-Hill Y: Measuring multiple fluxes through plant metabolic networks. Plant J 2006, 45:490-511.

31. Young JD, Shastri AA, Stephanopoulos G, Morgan JA: Mapping photoautotrophic metabolism with isotopically nonstationary ${ }^{13} \mathrm{C}$ flux analysis. Metab Engin 2011, 13:656-665.

32. Wolk CP, Shaffer PW: Heterotrophic micro- and macrocultures of a nitrogen-fixing cyanobacterium. Arch Microbiol 1976, 110:145-147.

33. Haury JF, Spiller H: Fructose uptake and influence on growth of and nitrogen fixation by Anabaena variabilis. J Bacterio/ 1981, 147:227-235.

34. Stebegg R, Wurzinger B, Mikulic M, Schmetterer G: Chemoheterotrophic growth of the cyanobacterium Anabaena sp. strain PCC 7120 dependent on a functional cytochrome c oxidase. J Bacteriol 2012, 194:4601-4607. 
35. Ungerer $J$, Pratte BS, Thiel T: Regulation of fructose transport and its effect on fructose toxicity in Anabaena spp. J Bacteriol 2008, 190:8115-8125.

36. Hu NT, Thiel T, Giddings TH Jr, Wolk CP: New Anabaena and Nostoc cyanophages from sewage settling ponds. Virology 1981, 114:236-246.

37. Allen MB, Arnon DI: Studies on nitrogen-fixing blue-green algae. I. Growth and nitrogen fixation by Anabaena cylindrica Lemm. Plant Physiol 1955, 30:366-372.

38. Lechno-Yossef S, Fan Q, Ehira S, Sato N, Wolk CP: Mutations in four regulatory genes have interrelated effects on heterocyst maturation in Anabaena sp. strain PCC 7120. J Bacteriol 2006, 188:7387-7395.

39. Elhai J, Wolk CP: Developmental regulation and spatial pattern of expression of the structural genes for nitrogenase in the cyanobacterium Anabaena. EMBO J 1990, 9:3379-3388.

40. Vioque A: The RNase P RNA from cyanobacteria: short tandemly repeated repetitive (STRR) sequences are present within the RNase P RNA gene in heterocyst-forming cyanobacteria. Nucleic Acids Res 1997, 25:3471-3477

41. Bolstad BM, Irizarry RA, Åstrand M, Speed TP: A comparison of normalization methods for high density oligonucleotide array data based on variance and bias. Bioinformatics 2003, 19:185-193.

42. The R Project for Statistical Computing. http://www.r-project.org/.

43. Sokal RR, RohIF FJ: Biometry. The Principles and Practice of Statistics in Biological Research, 2nd edn. New York: W. H. Freeman and Company; 1981

44. Hawkinson JE, AcostaBurruel M, Wood PL: The metabotropic glutamate receptor antagonist L-2-amino-3-phosphonopropionic acid inhibits phosphoserine phosphatase. Eur J Pharmacol 1996, 307:219-225.

45. D'Angelo E, Crutchfield J, Vandiviere M: Rapid, sensitive, microscale determination of phosphate in water and soil. J Environ Quality 2001 30:2206-2209.

46. Thiel T, Lyons EM, Erker JC, Ernst A: A second nitrogenase in vegetative cells of a heterocyst-forming cyanobacterium. Proc Natl Acad Sci U S A 1995, 92:9358-9362.

47. Golden JW, Whorff LL, Wiest DR: Independent regulation of nifHDK operon transcription and DNA rearrangement during heterocyst differentiation in the cyanobacterium Anabaena sp. strain PCC 7120. J Bacteriol 1991, 173:7098-7105

48. Kanehisa M, Goto S, Kawashima S, Okuno Y, Hattori M: The KEGG resource for deciphering the genome. Nucleic Acids Res 2004, 32:D277-D280.

49. Altschul SF, Madden TL, Schäffer AA, Zhang J, Zhang Z, Miller W, Lipman DJ: Gapped BLAST and PSI-BLAST: a new generation of protein database search programs. Nucleic Acids Res 1997, 25:3389-3402.

50. Jensen BB, Cox RP: Effect of oxygen concentration on dark nitrogen fixation and respiration in cyanobacteria. Arch Microbiol 1983, 135:287-292.

51. Murry MA, Wolk CP: Evidence that the barrier to the penetration of oxygen into heterocysts depends upon two layers of the cell envelope. Arch Microbiol 1989, 151:469-474

52. Valladares A, Herrero A, Pils D, Schmetterer G, Flores E: Cytochrome $c$ oxidase genes required for nitrogenase activity and diazotrophic growth in Anabaena sp. PCC 7120. Mol Microbiol 2003, 47:1239-1249.

53. Valladares A, Maldener I, Muro-Pastor AM, Flores E, Herrero A: Heterocyst development and diazotrophic metabolism in terminal respiratory oxidase mutants of the cyanobacterium Anabaena sp. strain PCC 7120. J Bacteriol 2007, 189:4425-4430

54. Brusca JS, Hale MA, Carrasco CD, Golden JW: Excision of an 11-kilobasepair DNA element from within the nifD gene in Anabaena variabilis heterocysts. J Bacteriol 1989, 171:4138-4145.

55. Schrautemeier B, Neveling U, Schmitz S: Distinct and differently regulated Mo-dependent nitrogen-fixing systems evolved for heterocysts and vegetative cells of Anabaena variabilis ATCC 29413: characterization of the $f d x H 1 / 2$ gene regions as part of the nif1/2 gene clusters. Mol Microbiol 1995, 18:357-369.

56. Thiel T: Isolation and characterization of the $\operatorname{VnfEN}$ genes of the cyanobacterium Anabaena variabilis. J Bacteriol 1996, 178:4493-4499.

57. Kanehisa M, Goto S: KEGG: Kyoto Encyclopedia of Genes and Genomes. Nucleic Acids Res 2000, 28:27-30.

58. Kanehisa M, Goto S, Sato Y, Furumichi M, Tanabe M: KEGG for integration and interpretation of large-scale molecular data sets. Nucleic Acids Res 2012, 40:D109-D114.

59. Gottschalk G: Bacterial Metabolism. New-York: Springer-Verlag; 1986.
60. EcoSal-Escherichia coli and Salmonella: Cellular and Molecular Biology. Edited by Böck A, Curtiss R III, Kaper JB, Karp PD, Neidhardt FC, Nyström T, Slauch JM, Squires CL, Usser D. Washington, DC: ASM Press. http://www. asmscience.org/content/journal/ecosalplus.

61. Wood NB, Haselkorn R: Control of phycobiliprotein proteolysis and heterocyst differentiation in Anabaena. J Bacteriol 1980, 141:1375-1385.

62. Maldener I, Lockau W, Cai Y, Wolk CP: Calcium-dependent protease of the cyanobacterium Anabaena: molecular cloning and expression of the gene in Escherichia coli, sequencing and site-directed mutagenesis. Mol Gen Genet 1991, 225:113-120.

63. Lahmi R, Sendersky E, Perelman A, Hagemann M, Forchhammer K, Schwarz $R$ : Alanine dehydrogenase activity is required for adequate progression of phycobilisome degradation during nitrogen starvation in Synechococcus elongatus PCC 7942. J Bacteriol 2006, 188:5258-5265.

64. Popa R, Weber PK, Pett-Ridge J, Finzi JA, Fallon SJ, Hutcheon ID, Nealson KH, Capone DG: Carbon and nitrogen fixation and metabolite exchange in and between individual cells of Anabaena oscillarioides. ISME J 2007, 1:354-360.

65. Herrero A, Flores E: Transport of basic amino acids by the dinitrogen-fixing cyanobacterium Anabaena PCC 7120. J Biol Chem 1990, 265:3931-3935.

66. Montesinos ML, Herrero A, Flores E: Amino acid transport systems required for diazotrophic growth in the cyanobacterium Anabaena sp. strain PCC 7120. J Bacteriol 1995, 177:3150-3157.

67. Picossi S, Montesinos ML, Pernil R, Lichtle C, Herrero A, Flores E: ABC-type neutral amino acid permease $\mathrm{N}-\mathrm{I}$ is required for optimal diazotrophic growth and is repressed in the heterocysts of Anabaena sp. strain PCC 7120. Mol Microbiol 2005, 57:1582-1592.

68. Pernil R, Picossi S, Mariscal V, Herrero A, Flores E: ABC-type amino acid uptake transporters Bgt and N-II of Anabaena sp. strain PCC 7120 share an ATPase subunit and are expressed in vegetative cells and heterocysts. Mol Microbiol 2008, 67:1067-1080.

69. Mullineaux CW, Mariscal V, Nenninger A, Khanum H, Herrero A, Flores E, Adams DG: Mechanism of intercellular molecular exchange in heterocyst-forming cyanobacteria. EMBO J 2008, 27:1299-1308

70. Merino-Puerto V, Schwarz H, Maldener I, Mariscal V, Mullineaux WW, Herrero A Flores E: FraC/FraD-dependent intercellular molecular exchange in the filaments of a heterocyst-forming cyanobacterium, Anabaena sp. Mol Microbiol 2011, 82:87-98.

71. Wilk L, Strauss M, Rudolf M, Nicolaisen K, Flores E, Kühlbrandt W, Schleiff E. Outer membrane continuity and septosome formation between vegetative cells in the filaments of Anabaena sp. PCC 7120. Cellular Microbiol 2011, 13:1744-1754.

72. Ernst $A, B o ̈ h m e ~ H$, Böger $P$ : Phosphorylation and nitrogenase activity in isolated heterocysts from Anabaena variabilis (ATCC 29413). Biochim Biophys Acta 1983, 723:83-90

73. Sicora Cl, Appleton SE, Brown CM, Chung J, Chandler J, Cockshutt AM, Vass I, Campbell DA: Cyanobacterial psbA families in Anabaena and Synechocystis encode trace, constitutive and UVB-induced D1 isoforms. Biochim Biophys Acta-Bioenergetics 2006, 1757:47-56.

74. Mulo P, Sakurai I, Aro EM: Strategies for $p s b A$ gene expression in cyanobacteria, green algae and higher plants: From transcription to PSII repair. Biochim Biophys Acta-Bioenergetics 1817, 2012:247-257.

75. Tel-Or E, Stewart WDP: Photosynthetic components and activities of nitrogen-fixing isolated heterocysts of Anabaena cylindrica. Proc Royal Soc London B 1977, 198:61-86.

76. Thomas J: Absence of the pigments of photosystem II of photosynthesis in heterocysts of a blue-green alga. Nature 1970, 228:181-183.

77. Donze M, Haveman J, Schiereck P: Absence of photosystem 2 in heterocysts of blue-green alga Anabaena. Biochim Biophys Acta 1972, 256:157-161.

78. Black K, Osborne B: An assessment of photosynthetic downregulation in cyanobacteria from the Gunnera-Nostoc symbiosis. New Phytologist 2004 162:125-132.

79. Enami I, Okumura A, Nagao R, Suzuki T, Iwai M, Shen JR: Structures and functions of the extrinsic proteins of photosystem II from different species. Photosynth Res 2008, 98:349-363.

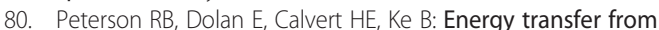
phycobiliproteins to photosystem I in vegetative cells and heterocysts of Anabaena variabilis. Biochim Biophys Acta 1981, 634:237-248.

81. Johnson TR, Haynes IIII, Wealand JL, Yarbrough LR, Hirschberg R: Structure and regulation of genes encoding phycocyanin and allophycocyanin from Anabaena variabilis ATCC 29413. J Bacteriol 1988, 170:1858-1865. 
82. Yeates TO, Kerfeld CA, Heinhorst S, Cannon GC, Shively JM: Protein-based organelles in bacteria: carboxysomes and related microcompartments. Nature Rev Microbiol 2008, 6:681-691.

83. Cannon GC, Heinhorst S, Kerfeld CA: Carboxysomal carbonic anhydrases: Structure and role in microbial $\mathrm{CO}_{2}$ fixation. Biochim Biophys Acta Proteins and Proteomics 1804, 2010:382-392.

84. Peña KL, Castel SE, de Araujo C, Espie GS, Kimber MS: Structural basis of the oxidative activation of the carboxysomal $\gamma$-carbonic anhydrase, CcmM. Proc Natl Acad Sci U S A 2010, 107:2455-2460.

85. Hagen KD, Meeks JC: The unique cyanobacterial protein OpcA is an allosteric effector of glucose-6-phosphate dehydrogenase in Nostoc punctiforme ATCC 29133. J Biol Chem 2001, 276:11477-11486.

86. Summers ML, Meeks JC: Transcriptional regulation of zwf, encoding glucose-6-phosphate dehydrogenase, from the cyanobacterium Nostoc punctiforme strain ATCC 29133. Mol Microbiol 1996, 22:473-480.

87. Winkenbach F, Wolk CP: Activities of enzymes of the oxidative and the reductive pentose phosphate pathways in heterocysts of a blue-green alga. Plant Physiol 1973, 52:480-483

88. Valverde F, Losada M, Serrano A: Functional complementation of an Escherichia coli gap mutant supports an amphibolic role for NAD(P)dependent glyceraldehyde-3-phosphate dehydrogenase of Synechocystis sp. strain PCC 6803. J Bacterio/ 1997, 179:4513-4522.

89. Valverde F, Peleato ML, Fillat MF, Gomez-Moreno C, Losada R, Serrano A: Simultaneous occurrence of two different glyceraldehyde-3-phosphate dehydrogenases in heterocystous $\mathrm{N}_{2}$-fixing cyanobacteria. Biochem Biophys Res Comm 2001, 283:356-363.

90. Schilling N, Ehrnsperger K: Cellular differentiation of sucrose metabolism in Anabaena variabilis. Z Naturforsch 1985, 40:776-779.

91. Curatti L, Giarrocco L, Salerno G: Sucrose synthase and RuBisCo expression is [sic] similarly regulated by the nitrogen source in the nitrogen-fixing cyanobacterium Anabaena sp. Planta 2006, 223:891-900.

92. Marcozzi C, Cumino AC, Salerno GL: Role of NtcA, a cyanobacterial global nitrogen regulator, in the regulation of sucrose metabolism gene expression in Anabaena sp. PCC 7120. Arch Microbiol 2009, 191:255-263.

93. Porchia AC, Salerno GL: Sucrose biosynthesis in a prokaryotic organism: presence of two sucrose-phosphate synthases in Anabaena with remarkable differences compared with the plant enzymes. Proc Natl Acad Sci U S A 1996, 93:13600-13604.

94. Cumino A, Ekeroth C, Salerno G: Sucrose-phosphate phosphatase from Anabaena sp. strain PCC 7120: isolation of the protein and gene revealed significant structural differences from the higher-plant enzyme. Planta 2001, 214:250-256.

95. Cumino AC, Marcozzi C, Barreiro R, Salerno GL: Carbon cycling in Anabaena sp. PCC 7120. Sucrose synthesis in the heterocysts and possible role in nitrogen fixation. Plant Physio/ 2007, 143:1385-1397.

96. Vargas W, Cumino A, Salerno GL: Cyanobacterial alkaline/neutral invertases. Origin of sucrose hydrolysis in the plant cytosol? Planta 2003, 216:951-960.

97. Curatti L, Flores E, Salerno G: Sucrose is involved in the diazotrophic metabolism of the heterocyst-forming cyanobacterium Anabaena sp. FEBS Lett 2002, 513:175-178.

98. Curatti L, Giarrocco LE, Cumino AC, Salerno GL: Sucrose synthase is involved in the conversion of sucrose to polysaccharides in filamentous nitrogen-fixing cyanobacteria. Planta 2008, 228:617-625.

99. Amor $Y$, Haigler $\mathrm{CH}$, Johnson S, Wainscott M, Delmer DP: A membraneassociated form of sucrose synthase and its potential role in synthesis of cellulose and callose in plants. Proc Natl Acad Sci U S A 1995 92:9353-9357.

100. Lang NJ, Krupp JM, Koller AL: Morphological and ultrastructural changes in vegetative cells and heterocysts of Anabaena variabilis grown with fructose. J Bacteriol 1987, 169:920-923.

101. Huang G, Fan Q, Lechno-Yossef S, Wojciuch E, Wolk CP, Kaneko T, Tabata S: Clustered genes required for the synthesis of heterocyst envelope polysaccharide in Anabaena sp. strain PCC 7120. J Bacteriol 2005, 187:1114-1123.

102. Summers ML, Wallis JG, Campbell EL, Meeks JC: Genetic evidence of a major role for glucose-6-phosphate dehydrogenase in nitrogen fixation and dark growth of the cyanobacterium Nostoc sp. strain ATCC 29133. J Bacterio/ 1995, 177:6184-6194.
103. Wolk CP, Thomas J, Shaffer PW, Austin SM, Galonsky A: Pathway of nitrogen metabolism after fixation of ${ }^{13} \mathrm{~N}$-labeled nitrogen gas by the cyanobacterium, Anabaena cylindrica. J Biol Chem 1976, 251:5027-5034

104. Papen $H$, Neuer $G$, Refaian $M$, Bothe $H$ : The isocitrate dehydrogenase from cyanobacteria. Arch Microbiol 1983, 134:73-79.

105. Galmozzi CV, Saelices L, Florencio FJ, Muro-Pastor Ml: Posttranscriptional regulation of glutamine synthetase in the filamentous cyanobacterium Anabaena sp. PCC 7120: differential expression between vegetative cells and heterocysts. J Bacteriol 2010, 192:4701-4711.

106. Meeks JC, Wolk CP, Thomas J, Lockau W, Shaffer PW, Austin SM, Chien WS, Galonsky A: The pathways of assimilation of ${ }^{13} \mathrm{NH}_{4}{ }^{+}$by the cyanobacterium, Anabaena cylindrica. J Biol Chem 1977, 252:7894-7900

107. Chávez S, Lucena JM, Reyes JC, Florencio FJ, Candau P: The presence of glutamate dehydrogenase is a selective advantage for the cyanobacterium Synechocystis sp. strain PCC 6803 under nonexponential growth conditions. J Bacteriol 1999, 181:808-813.

108. Ke S, Haselkorn R: The Sakaguchi reaction product quenches phycobilisome fluorescence, allowing determination of the arginine concentration in cells of Anabaena strain PCC 7120. J Bacteriol 2013, 195:25-28.

109. Prasil O, Kolber Z, Berry JA, Falkowski PG: Cyclic electron flow around photosystem II in vivo. Photosynth Res 1996, 48:395-410.

110. Long BM, Rae BD, Badger MR, Price GD: Over-expression of the betacarboxysomal CcmM protein in Synechococcus PCC7942 reveals a tight co-regulation of carboxysomal carbonic anhydrase (CcaA) and M58 content. Photosynth Res 2011, 109:33-45.

doi:10.1186/1471-2164-14-759

Cite this article as: Park et al:: Cell-specific gene expression in Anabaena variabilis grown phototrophically, mixotrophically, and heterotrophically. BMC Genomics 2013 14:759.

\section{Submit your next manuscript to BioMed Central and take full advantage of:}

- Convenient online submission

- Thorough peer review

- No space constraints or color figure charges

- Immediate publication on acceptance

- Inclusion in PubMed, CAS, Scopus and Google Scholar

- Research which is freely available for redistribution 